PALABRAS CLAVE

CEPAL

Desarrollo económico

Política económica

Reforma económica

Historia

Macroeconomía

Comercio internacional

Desarrollo social

Desarrollo sostenible

América Latina

Caribe

Ricardo Bielschowsky

Oficial de Asuntos Económicos,

Oficina de la CEPAL,

Brasilia

— ricardo.bielschowsky@cepal.org
REVISTA CEPAL 97 - ABRIL 2009

\section{Sesenta años de la CEPAL: estructuralismo y neoestructuralismo}

\author{
Ricardo Bielschowsky
}

$\mathrm{E}$

n este documento se analizan el pensamiento y las ideas fuerza generados por la CEPAL a lo largo de sus seis decenios de existencia, mediante una revisión de los trabajos realizados desde su creación en 1948 en que se distingue entre las etapas estructuralista (decenios de $1950,1960,1970$ y 1980) y neoestructuralista (desde 1990). Se examinan luego las contribuciones más relevantes del período 1998-2008, entre las cuales destacan los efectos de las reformas estructurales de los años noventa; la agenda para la era global; los enfoques en materia de derechos, ciudadanía y cohesión social; la fusión schumpeterianaestructuralista, y las políticas macroeconómicas anticíclicas en condiciones de volatilidad financiera. Se abordan las similitudes y diferencias entre ambas fases y se concluye que el neoestructuralismo ha guardado gran proximidad analítica con el estructuralismo. 


\section{I}

\section{Introducción}

El presente artículo sintetiza la evolución del pensamiento de la Comisión Económica para América Latina y el Caribe (CEPAL) en sus 60 años de existencia, mediante una revisión sistemática del extenso material bibliográfico publicado por la institución, con énfasis en el sexto decenio.

Se observa que, en general, los textos de las tres primeras décadas estudiados en este trabajo son principalmente los suscritos por los intelectuales más destacados de la CEPAL en ese período, mientras que los utilizados en referencia al pensamiento de los tres últimos decenios corresponden más bien a documentos oficiales de la institución.

Se reproduce en este trabajo, con la debida extensión a la sexta década, la clasificación periódica utilizada en un artículo anterior sobre las cinco primeras décadas (Bielschowsky, 1998), organizada en torno a los "mensajes" que impulsaron la producción intelectual de la institución y que reflejaban el contexto histórico de cada momento. ${ }^{1}$

Las ideas centrales de los primeros 30 años fueron la industrialización (década de 1950); la necesidad de aplicar reformas en los ámbitos fiscal, financiero, agrario y administrativo, entre otros, para profundizar la industrialización y reducir las desigualdades (década de 1960) y la reorientación de los "estilos" de desarrollo (década de 1970).

En el decenio de 1980, a raíz de la crisis de la deuda se produjo un inevitable cambio de prioridades en el enfoque de la CEPAL, que se trasladó así desde el binomio producción-distribución prevaleciente hasta entonces a los temas macroeconómicos.

\footnotetext{
$\square$ Versión reducida y levemente modificada de la introducción al libro conmemorativo del $60^{\circ}$ aniversario de la CEPAL, cuya publicación está pendiente, en que se presenta una selección de los documentos publicados entre 1998 y 2008. El autor agradece a los numerosos colegas que colaboraron en la investigación y que hicieron valiosos comentarios sobre el texto original, en especial a Miguel Torres por su excelente aporte al presente trabajo. Naturalmente, la interpretación y las eventuales omisiones o imprecisiones son responsabilidad del autor.

${ }^{1}$ Sobre la evolución de las ideas de la CEPAL, véanse, entre otros, Hirschman (1963), Cardoso (1977), CEPAL (1969), Rodríguez (1981, 2006), Gurrieri (1982), Pazos (1983), Hodara (1987), Fitzgerald (1994), Hettne (1995) Bielschowsky (1998), Rosenthal (2004) y Love (2005).
}

A partir de 1990, y sin desatender la necesidad de conquistar y preservar la estabilidad macroeconómica, el foco principal volvió a ser el de las reformas de largo plazo. El mensaje que pasó a dominar el temario de investigación y reflexión de la CEPAL, la transformación productiva con equidad, contenía los dos objetivos prioritarios expresados tradicionalmente por la institución: desarrollar una base productiva en que se conjugaran un aumento continuo de la productividad y una inserción internacional competitiva y construir una sociedad más igualitaria y justa.

En el decenio de 1990, la CEPAL actualizó su pensamiento para adecuarlo a la nueva realidad de apertura comercial, movilidad internacional de capitales, privatización y desregulación, en un contexto de relaciones más estrechas con el resto del mundo y de mayor integración regional. Lo hizo conservando los elementos centrales del enfoque estructuralista inaugural y formulando estrategias y políticas alternativas en buena medida discrepantes con las de la agenda neoliberal. Para caracterizar a esta nueva etapa se utilizó, con razón, la expresión "neoestructuralismo".

Entre 1998 y 2008 se enriquecieron, maduraron y perfeccionaron los análisis y propuestas neoestructuralistas, configurándose así una agenda de políticas que abarca los cuatro campos analíticos fundamentales de la CEPAL: macroeconomía y finanzas, desarrollo productivo y comercio internacional, desarrollo social y sostenibilidad ambiental. Este programa reciente - heterodoxo en materia macroeconómica, desarrollista en cuanto a asignación de recursos e intervención del Estado, universalista en el campo social y conservacionista en materia ambiental - figura en los principales textos oficiales de la CEPAL, a los cuales se hará referencia en este trabajo, así como en un sinnúmero de artículos firmados por sus investigadores.

La lectura de esos documentos permite afirmar que el pensamiento de la institución se caracteriza por la continuidad y el cambio. A lo largo de su historia, la CEPAL ha mantenido el mismo enfoque metodológico y analítico, conservando la unidad y coherencia de su producción intelectual, pero actualizando los análisis en forma permanente. Como se observa en el libro Cincuenta años del pensamiento de la CEPAL: textos seleccionados, "lo que se va modificando es la historia 
real objeto del análisis, así como el contexto ideológico en que ésta se genera, lo que obliga permanentemente a matizar los énfasis y a renovar las interpretaciones, a fin de adaptarse a los nuevos contextos históricos" (CEPAL, 1998a).

Así lo confirma la transición hacia el neoestructuralismo, que obedeció al cambio histórico de las condiciones internas e internacionales, es decir, a la inestabilidad macroeconómica que se instaló en los años setenta tras la falencia del sistema de Bretton Woods y, desde fines de los años ochenta, a la reorientación de las economías de la región hacia la desregulación y la globalización. Ello condujo a la CEPAL a revisar su postura analítica y proposicional, a fin de adecuarla a los nuevos tiempos. Sin embargo, en esa revisión se preservó el instrumental analítico acumulado, poniéndolo al servicio de una "agenda positiva" para el desarrollo económico y social de la región, alternativa y opuesta a las concepciones del pensamiento ortodoxo en materia macroeconómica y neoliberal relativo a asignación de recursos.

El presente artículo contiene tres secciones, además de esta introducción y de la conclusión. En la segunda sección se presenta una síntesis de las principales ideas generadas por la institución en la etapa estructuralista - los primeros 40 años- $y$, en la tercera, del pensamiento de la etapa neoestructuralista vigente desde 1990. La cuarta sección muestra la proximidad de los análisis realizados en ambas etapas. ${ }^{2}$

\section{II}

\section{La etapa estructuralista (1948-1990)}

El sistema analítico de la CEPAL se basa en el método "histórico-estructural", que examina las especificidades productivas, sociales, institucionales y de inserción internacional de los países de América Latina y el Caribe en su carácter de "periféricos", en contraposición a las características de las economías "centrales" observadas desde la perspectiva prioritaria de su transformación a mediano y largo plazo. El enfoque se originó en los tres textos fundacionales con que Prebisch orientó teórica e ideológicamente a la institución (CEPAL, 1951a y 1951b; Prebisch, 1973), que fue profundizado durante las dos décadas subsiguientes por el autor y algunos de sus seguidores. ${ }^{3}$

\footnotetext{
${ }^{2}$ El enfoque estructuralista se vinculó estrechamente a la producción del "desarrollismo", representada por nombres como los de Rosenstein Rodan, Singer, Nurkse, Lewis Myrdal, Hirschman y otros pioneros de esta corriente. En el período reciente, a partir de la contribución inicial de Fajnzylber, los intelectuales de la CEPAL se cuentan entre quienes han buscado interpretaciones y políticas alternativas a las neoliberales, como Taylor y Shapiro (1990), Amsden (1989) y Wade (1990), entre otros. Sin embargo, el presente trabajo no aborda las divergencias y convergencias entre el pensamiento de la institución y el que se encuentra documentado en la literatura especializada del resto del mundo.

${ }^{3}$ El método histórico-estructural permite una fértil interacción de los enfoques deductivo e histórico-interpretativo, ocupándose de la trayectoria de los agentes e instituciones y del diálogo permanente entre las formulaciones teóricas y los cambios históricos. El libro de Furtado (1959) sobre la formación económica del Brasil es, posiblemente, la referencia más importante en cuanto a la utilización del método en el estudio de la historia. Para una discusión de este, véase, por ejemplo, Sunkel y Paz (1970), capítulo 5.
}

De acuerdo con la trilogía inaugural, en comparación con los países centrales, productores de bienes industrializados, la estructura socioeconómica de la región presentaba las siguientes características: ${ }^{4}$ i) especialización en bienes del sector primario y baja diversidad productiva (complementariedad intersectorial e integración vertical reducidas); ii) niveles muy dispares de productividad sectorial ${ }^{5}$ y oferta ilimitada de mano de obra con ingresos próximos a la subsistencia, y iii) estructura institucional (Estado, sector agrario y composición empresarial, entre otros) poco inclinada a la inversión y al progreso técnico.

La industrialización, que se había fortalecido como respuesta a la recesión de los años treinta y de la Segunda Guerra Mundial y progresaba en forma espontánea — sin el apoyo de políticas de fomento-, era la fórmula para superar la pobreza y revertir la distancia creciente entre la periferia y el centro. No obstante, se perfilaba como muy problemática debido a las características señaladas de la estructura socioeconómica.

En efecto, para diversificar la escasa base productiva se requería invertir simultáneamente en muchos sectores, lo que suponía un gran esfuerzo adicional en materia de divisas y ahorro, en circunstancias que

\footnotetext{
${ }^{4}$ Octavio Rodríguez (1981) ofrece una visión detallada y precisa de las formulaciones de Prebisch, en las cuales se basó esta recapitulación de los elementos clave del pensamiento prebischiano.

${ }^{5}$ Más tarde, en los años sesenta, Pinto $(1965,1970)$ utilizaría la expresión "heterogeneidad estructural" para referirse a esta disparidad.
} 
la especialización en bienes primarios generaba una oferta muy limitada de divisas en un contexto histórico caracterizado por las fuertes presiones sobre la demanda de ellas. Por otra parte, la coexistencia de un pequeño sector de productividad elevada con otro más amplio de menor dinamismo configuraba una heterogeneidad estructural en que la proporción excedente-ingreso era muy reducida. A su vez, el atraso institucional se traducía en capacidad fiscal insuficiente, desperdicio de parte del excedente en inversiones improductivas y consumo superfluo, así como un magro estímulo de la inversión y el avance tecnológico.

Las tres características citadas del subdesarrollo y de la "condición periférica" de América Latina constituyen los aspectos esenciales en torno a los cuales se han estructurado el trabajo intelectual y los niveles analíticos tradicionalmente explorados por la CEPAL: progreso técnico, crecimiento, empleo, distribución del ingreso y pobreza; inserción internacional en el ámbito de las relaciones "centro-periferia" y planificación y diseño de las implicaciones de política económica. ${ }^{6}$ Más adelante, al examinar el pensamiento reciente, subrayaremos el hecho de que estos elementos aún están presentes en el análisis cepalino.

La superación de la "condición periférica" suponía, en opinión de los intelectuales más connotados de los primeros tiempos de la institución (Prebisch, Furtado, Medina Echavarría, Noyola Vázquez, Ahumada, Pinto y Sunkel, entre otros), una modalidad propia de introducir el progreso técnico, de distribuir el ingreso y de relacionarse con el resto del mundo. Por eso, estos autores sostenían que era necesario formular una teoría autónoma capaz de aprehender la naturaleza del subdesarrollo de la región y las vicisitudes de su evolución socioeconómica. No fueron pocas las contribuciones analíticas generadas por los investigadores de la CEPAL a partir de la inspiración estructuralista. Con independencia y audacia, esa producción contribuyó al diseño de una identidad ideológica para la región en su conjunto.

Durante la primera década, dedicada al mensaje de la industrialización, tal vez el principal aporte haya sido la idea prebischiana de que había una asimetría básica entre el escaso dinamismo de la demanda mundial de productos primarios originados en la periferia y la amplia demanda periférica de productos industriales fabricados

\footnotetext{
${ }^{6}$ La interpretación de que el proceso era muy problemático dio lugar a todo un trabajo de formulación sobre técnicas de programación inaugurado en 1952 (CEPAL, 1955) y, más tarde, a la creación del Instituto Latinoamericano y del Caribe de Planificación Económica y Social (ILPES).
}

en el centro. Esta asimetría tendría consecuencias potencialmente fatales para el desarrollo de los países de la región, porque tendería a provocar un desequilibrio de carácter estructural en la balanza de pagos, con efectos adversos en la inflación y la continuidad del crecimiento. Además, se señalaba que las dificultades se acentúan por el hecho de que, a diferencia de los beneficios prometidos por los defensores del libre comercio, se produce un deterioro de los términos de intercambio en perjuicio de los países subdesarrollados.

La atención prestada a la vulnerabilidad externa y a la escasez de divisas, que junto con la falta de ahorro e inversión eran vistas como el principal obstáculo al crecimiento, conduciría al análisis de las causas determinantes del proceso de industrialización, es decir, de la dinámica de la sustitución de importaciones. ${ }^{7}$ También incidiría decisivamente en la interpretación estructuralista de la inflación latinoamericana por Noyola Vázquez (1957) y Osvaldo Sunkel (1958), cuya contribución fundamental consistió en apuntar a la posibilidad teórica de que en ciertas circunstancias la causa primaria de la inflación no fuera la expansión monetaria, sino los desajustes en la balanza de pagos y otros problemas propios de la estructura subdesarrollada de América Latina.

Al mismo tiempo, la cuestión de la vulnerabilidad externa fue un aspecto fundamental de los análisis formulados en los años cincuenta para establecer un mercado regional —en Centroamérica y, después, en América Latina en su conjunto-, entendido en esa época como mecanismo que permitiría ampliar la industrialización y atenuar el problema de falta de divisas (CEPAL, 1959). ${ }^{8}$ Años después, tras la creación de la Conferencia de las Naciones Unidas sobre Comercio y Desarrollo (UNCTAD), liderada por Prebisch, también sería un elemento central de las propuestas relacionadas con la necesidad de regular las reservas (stocks) internacionales de bienes primarios y de crear esquemas preferenciales de acceso a los mercados centrales para los productos primarios e industriales de los países en desarrollo.

En los años sesenta, al mensaje en favor de la "industrialización" se incorporó un componente adicional: la propuesta de efectuar reformas institucionales - agraria, fiscal y financiera, entre otras- que se consideraba indispensables para permitir la continuidad y profundización del desarrollo industrial. Al mismo tiempo, en una CEPAL

\footnotetext{
${ }^{7} \mathrm{El}$ análisis lo realizaron Prebisch en los textos inaugurales y Tavares (1964) en forma más acabada, ya en los años sesenta.

${ }^{8}$ En cuanto a la participación de la CEPAL en la creación del mercado centroamericano, véase el relato ofrecido por uno de sus grandes inspiradores, Víctor Urquidi (1998).
} 
menos optimista que en la década anterior, y como reacción al hecho de que el éxito relativo de la industrialización no había impedido que aumentara considerablemente la pobreza urbana, surgieron las primeras formulaciones sobre sus efectos en los planos del empleo y la distribución del ingreso. De ahí en adelante, la cuestión de la equidad pasaría a vincularse con el tema del desarrollo productivo en la agenda de la institución. Ello representó un importante avance respecto de los trabajos de la década anterior, en que prácticamente no se había tratado esta temática.

Furtado (1961) formuló la tesis de la persistencia del subempleo - y, por ende, del subdesarrollo- a lo largo del proceso de industrialización. A las interpretaciones anteriores de la CEPAL sobre la propensión al desequilibrio estructural de la balanza de pagos y la inflación, se sumaba ahora la evidencia de una nueva modalidad de pobreza y desequilibrio social, crecientemente urbano y simultáneo a la modernización promovida por la industrialización.

Fue entonces que surgió en la CEPAL el análisis que vinculaba la pobreza y la distribución desigual del ingreso con el aumento de las disparidades en materia de productividad y remuneración del trabajo entre personas, sectores y regiones. Se originó así el concepto de heterogeneidad estructural, interpretada como resultado de las condiciones históricas heredadas y de la evolución natural del mercado de trabajo. Su argumento central es que, en perjuicio del trabajador, la oferta abundante de mano de obra se acompaña de una lenta expansión de su demanda, esta última debido al escaso ritmo de crecimiento de las inversiones y al predominio de una elevada intensidad de capital.

Fueron años de abundante producción de ideas sobre la relación entre la dinámica de la distribución del ingreso y del crecimiento en las condiciones de la nueva heterogeneidad socioeconómica, como las que realizaron Pinto (1965, 1970), Furtado (1969) y Tavares y Serra (1971). Al mismo tiempo, como consecuencia del creciente ingreso de capitales extranjeros a la región, fueron años de fecundo debate sobre el carácter dependiente del proceso de modernización latinoamericano, en el que destacaron Sunkel (1971) en la interpretación económica y Cardoso y Faletto (1969) en la interpretación política.

En los años setenta, el pensamiento de la CEPAL seguiría avanzando en torno a sus dos carriles fundamentales, a saber, la naturaleza y dificultades del crecimiento económico y el desarrollo industrial y la distribución del ingreso.

En cuanto al primero de ellos, continuó el debate iniciado en la década anterior sobre las insuficiencias de la industrialización, en que se habían cuestionado las limitaciones que representaba el exceso de protección y la ausencia de una institucionalidad que favoreciera la inversión y el progreso técnico. Sin embargo, ante una oleada liberalizadora introducida en los países del Cono Sur en los años setenta, la CEPAL adoptó una actitud reservada frente a posibles revisiones del marco regulatorio de la actividad económica, pese a que desde comienzos de los años sesenta muchos de sus intelectuales habían reconocido que este era excesivamente proteccionista (por ejemplo, Prebisch, 1961 y 1982; Macario, 1964). En su lugar, se proponía incentivar las exportaciones orientadas a los ámbitos regional y mundial. La expansión simultánea del mercado interno y de la exportación de bienes industriales - combinación que en ese entonces daba sus primeros pasos en países tales como Brasilse consideraba el mecanismo esencial para enfrentar el problema de la vulnerabilidad externa, de manera que a partir de los primeros años de la década de 1970 pasó a presentarse como opción contrapuesta al endeudamiento externo, que fue objeto de advertencias contundentes en cuanto a los riesgos que implicaba recurrir a él en exceso (CEPAL, 1971).

En lo relativo a la distribución del ingreso, maduró el debate sobre estilos o modalidades de desarrollo merced al análisis de la relación entre la estructura de la demanda (distribución del ingreso) y de la oferta (acumulación de capital y progreso técnico) y a la comprobación de que el modelo predominante perpetuaba la desigualdad y no permitía enfrentar adecuadamente la pobreza. El mensaje señalaba la necesidad de redistribuir el ingreso - lo que según se entendía exigía recuperar la democracia, a la sazón eliminada en buena parte de la región- como forma de hacer políticamente viable un estilo más justo de crecimiento.

En los años ochenta, denominados "la década perdida" debido a la caída del ingreso per cápita regional originada por la crisis de la deuda, el trabajo de la CEPAL estuvo condicionado por el contexto de los ajustes recesivos practicados en gran parte de los países de la región. Ello condujo a reducir la importancia relativa de los dos temas hasta entonces principales - desarrollo productivo e igualdad - y a reorientar las prioridades a un campo en que la institución no había intervenido mayormente en los decenios anteriores, a saber, el análisis de la estabilidad macroeconómica y sobre todo de la trilogía deuda-inflación-ajuste.

Entre los mensajes de la CEPAL se contaba renegociar la deuda externa para permitir el ajuste con crecimiento. Cabe mencionar que en los años ochenta no había una convergencia perfecta de sus cuadros técnicos y 
dirigentes en cuanto a la forma de abordar el problema, es decir, entre proximidad o alejamiento de la perspectiva del Fondo Monetario Internacional (FMI) y de la banca y entre mayor o menor heterodoxia en la lucha contra el proceso inflacionario. ${ }^{9}$ En general, prevaleció la visión de la corriente heterodoxa, que hacía hincapié en que era preciso combinar el control de la inflación con la renegociación de la deuda para permitir la recuperación del crecimiento y la inversión. Era la fórmula propuesta para evitar a corto plazo los grandes sacrificios a que los acreedores estaban sometiendo a los países de la región y para alcanzar a mediano y largo plazos la competitividad de las exportaciones. Se expresaba así un mensaje que coincidía con la tradición de la CEPAL, porque se señalaba que más allá de afrontar las dificultades de corto plazo, la solución estructural de los problemas externos requería aumentar y diversificar la producción $\mathrm{y}$ las exportaciones.

En los años ochenta, la relativa supremacía de las reflexiones en torno a la macroeconomía no impidió que continuara el interés por la temática del desarrollo económico, en sus esferas productiva y distributiva. El mejor momento en este sentido fue tal vez la formulación de las tesis de Fernando Fajnzylber (1983, 1990). Cuando ingresó a la CEPAL, en 1983, el autor acababa de terminar el libro La industrialización trunca de América Latina. Esta obra, junto con Industrialización en América Latina: de la caja negra al casillero vacío, divulgada a fines de la década, fueron los principales textos de referencia para la revisión del estructuralismo y el arraigo de la etapa "neoestructuralista" iniciada en 1990. ${ }^{10}$

Fajnzylber era contrario al neoliberalismo emergente y entendía que el desarrollo supone un papel importante del Estado, pero era muy crítico del modelo de desarrollo adoptado en esa época, así como de la institucionalidad que lo acogía. Naturalmente, la oposición de Fajnzylber al neoliberalismo durante los años ochenta no se aparta de las numerosas discrepancias con esa ideología que se dieron a conocer en los trabajos mundiales del período sobre la temática del desarrollo. Sin embargo, las formulaciones del autor han sido particularmente relevantes para la CEPAL, ya que desde el punto de vista analítico fue quien condujo a la institución hacia la etapa neoestructuralista, en la que se evaluarían las oportunidades y desafíos para el desarrollo en economías abiertas y con Estados activos pero menos intervencionistas. Asimismo, su énfasis en el progreso técnico basado en la acumulación de conocimientos — que en parte derivó de los estudios neoschumpeterianos sobre la revolución representada por las tecnologías de la información y la biotecnología y la creación de sistemas nacionales de innovaciónhabría de establecer una nueva referencia analítica en el pensamiento de la CEPAL.

\section{III}

\section{La etapa neoestructuralista (1990-2008)}

\section{Una breve reseña de su evolución}

A fines de los años ochenta, casi todos los países de América Latina y el Caribe avanzaban aceleradamente hacia la apertura comercial y financiera, la privatización y la reducción de la intervención estatal en general. Como se sabe, el contexto político e ideológico internacional de ese momento era muy desfavorable para la heterodoxia y hostil a las formulaciones clásicas de la CEPAL debido a su escepticismo y prudencia en relación con la liberalización del comercio y otras desregulaciones. Ante la sensación de irreversibilidad histórica de tales reformas y la necesidad de dialogar

\footnotetext{
${ }^{9}$ En cuanto a las divergencias, véase, por ejemplo, Marinho (1991).
}

con los países miembros de la organización, Gert Rosenthal —quien sucedió a Norberto González como Secretario Ejecutivo en 1988 y encabezó la producción intelectual de la institución hasta fines de 1997- acogió e impulsó las ideas de Fajnzylber para posicionarlas en el debate ideológico de la época, reconociendo las reformas institucionales pero oponiéndose a una serie de elementos centrales de la liberalización orientada por el Consenso de Washington. Durante el mandato de Rosenthal, la CEPAL adoptó las contribuciones de Fajnzylber como base para diseñar una nueva estrategia de desarrollo productivo, social y de inserción internacional.

\footnotetext{
${ }^{10}$ Sunkel (1991) también contribuyó al inicio de esta nueva etapa.
} 
Las investigaciones sobre el funcionamiento de las economías latinoamericanas y caribeñas en las nuevas circunstancias históricas pasaron a ocupar un lugar fundamental en la institución, junto con la formulación de estrategias y políticas alternativas a la agenda reformista ortodoxa para el desarrollo de la región. Los análisis e implicaciones de política se basaron en una revisión selectiva y transformadora de las reformas recomendadas por la ortodoxia, haciendo hincapié en el objetivo de crecimiento con equidad distributiva.

Efectivamente, como se dijo en la introducción, los textos elaborados a partir de 1990 contienen propuestas contundentes de revisión de la apertura financiera y el manejo macroeconómico en un contexto de volatilidad de los capitales financieros; aplicación de nuevas políticas industriales, tecnológicas y comerciales; reorientación de las reformas previsionales y diseño de políticas sociales en diferentes áreas, así como intervenciones públicas en materia de sostenibilidad ambiental.

La fórmula neoestructuralista permitió tender un puente con los gobiernos latinoamericanos y caribeños que habían adherido a las reformas, sin abandonar la construcción analítica estructuralista original e insistiendo en la necesidad urgente de implementar políticas de transformación social y económica para superar el subdesarrollo, más allá del funcionamiento del libre mercado. Si para algunos ello significó rendirse al neoliberalismo, para otros fue una alternativa que permitiría seguir incidiendo en los destinos de la región desde la perspectiva teórica y metodológica clásica de la CEPAL. La lectura de los principales textos de las décadas de 1990 y 2000 refuerza esta última interpretación.

A partir de 1990, la institución flexibiliza, entonces, el concepto de políticas de desarrollo que había acompañado al estructuralismo clásico en las cuatro décadas anteriores. Pero al mismo tiempo que admite la inevitabilidad de cambiar el marco regulatorio, analiza críticamente las reformas, señalando tanto sus méritos como sus errores e insuficiencias. Se reconoce la necesidad de revisar la participación del Estado en la vida económica y los instrumentos y mecanismos de intervención, pero se sigue asignando un papel clave a su contribución en la agenda de desarrollo socioeconómico en los ámbitos financiero, productivo, social y ambiental.

El documento Transformación productiva con equidad (CEPAL, 1990), presentado en el vigésimo tercer período de sesiones y coordinado por Rosenthal y Fajnzylber, contiene los planteamientos básicos de esta nueva etapa. Se propone una mayor apertura comercial impulsada en forma gradual y selectiva y reforzada por un tipo de cambio real elevado y estable, como parte de un proyecto orientado a lograr una competitividad "auténtica", es decir, basada en el fortalecimiento de la capacidad productiva y de innovación. En este sentido, se subraya el carácter sistémico de la competitividad, priorizando la creación de infraestructura física, la formación de recursos humanos y las políticas de innovación y progreso técnico para alcanzar un crecimiento más elevado y sostenido y una inserción internacional exitosa.

Con esta propuesta, la CEPAL introducía nuevamente en el debate sus temas de preocupación permanente: el crecimiento de largo plazo y la justicia social. Fajnzylber aportó varias ideas fuerza al mensaje de Transformación productiva con equidad, renovando la visión cepalina del desarrollo. Sostuvo que tanto la equidad como el progreso técnico son fundamentales para elevar la productividad y la competitividad, distinguiendo entre la competitividad auténtica y la espuria. La primera surge de la aplicación constante y creciente de nuevas tecnologías, la calificación del capital humano y la equidad, mientras que la segunda se basa en ventajas cambiarias, salariales y de recursos naturales. Por otra parte, subrayaba la relevancia de la industria por ser el sector de mayor potencial de contenido y difusión de progreso técnico, pero a la vez señalaba que esta debía articularse con los demás sectores para favorecer los efectos de derrame (spillovers) y los encadenamientos productivos. También propuso una amplia concertación social en torno a la innovación y el cambio técnico. Consideraba clave el papel de las instituciones y valoraba la democracia, ya que esta permitía materializar la transformación productiva y social (Torres, 2006).

A partir de entonces, las ideas se profundizaron en una serie de textos, sobre todo en los documentos de los períodos de sesiones siguientes. Al respecto, cabe citar las propuestas relativas al requisito de simultaneidad entre la equidad y la transformación productiva y al análisis de sus complementariedades (CEPAL, 1992), así como la que centra la atención en la educación y el conocimiento como ejes fundamentales de la transformación productiva con equidad (CEPAL/UNESCO, 1992).

Es también el caso de las políticas encaminadas a mejorar la inserción en la economía internacional, entre las que cabe mencionar el control de las corrientes de capital extranjero de corto plazo y la regulación estricta de las finanzas (CEPAL, 1995), la aceleración del crecimiento para lograr cambios significativos en materia de transformación productiva, aumento de la 
productividad y equidad (CEPAL, 1996) y la orientación hacia el "regionalismo abierto" (CEPAL, 1994). ${ }^{11}$

Asimismo, la revisión abarcó las recomendaciones en el ámbito fiscal, simbolizadas por el concepto de pacto fiscal (CEPAL, 1998b), con un método que procura conciliar las demandas sociales con el saneamiento de las finanzas públicas y el equilibrio macroeconómico, en condiciones de maduración progresiva de las prácticas democráticas. El documento aborda la consolidación del ajuste fiscal, el aumento de la productividad de la gestión pública y de la transparencia, el fomento de la equidad y el fortalecimiento de la institucionalidad democrática. ${ }^{12}$

En su sexta década de existencia, la CEPAL continuó el trabajo de los 50 años anteriores, orientándose especialmente al perfeccionamiento y maduración de los planteamientos neoestructuralistas de los años noventa. Para ello, pudo evaluar los resultados de las reformas liberalizadoras a la luz del desempeño económico y social de la región y tras casi una década de intensas discusiones al respecto. Asimismo, el pensamiento de la institución evolucionó en medio de una distensión significativa del debate ideológico, provocada por el debilitamiento del pensamiento neoliberal hegemónico en la región debido a las sucesivas perturbaciones cíclicas de fines del decenio de 1990 y comienzos del actual.

En el curso de la sexta década hubo dos coyunturas distintas: la primera mitad (1998-2003) se caracterizó por la lentitud del crecimiento económico mundial y regional tras la oleada de crisis financieras (asiática, rusa, argentina) y la segunda (2003-2008), por la expansión económica acelerada tanto del mundo como de la mayoría de los países de la región. No obstante el panorama económico favorable del segundo quinquenio, no se desarticuló el mayor equilibrio ideológico materializado en el escenario internacional desde fines de los noventa entre el neoliberalismo y las visiones que lo impugnaron. Lo mismo puede decirse del contexto ideológico regional, en que se observó además el surgimiento de varios gobiernos cuyos discursos y programas discrepaban del ideario antes hegemónico.

\footnotetext{
${ }^{11} \mathrm{El}$ autor del documento sobre regionalismo abierto es Gert Rosenthal. Los demás estudios citados fueron supervisados por Rosenthal y coordinados, respectivamente, por Fajnzylber y Ramos, Fajnzylber y Ottone, Ffrench-Davis y Altimir. Rosales participó en todos ellos.

${ }^{12}$ Este documento fue preparado en el período de transición entre la gestión del Secretario Ejecutivo Gert Rosenthal y la de su sucesor, José Antonio Ocampo, de 1997 a 1998. Consolidó una reflexión sobre la problemática fiscal de América Latina y el Caribe realizada en la CEPAL durante más de una década, bajo la coordinación de Juan Carlos Lerda (2008).
}

En el primer quinquenio citado, la CEPAL fue dirigida por José Antonio Ocampo y en el segundo por José Luis Machinea. Hubo una armonía analítica en los trabajos de ambos períodos, apreciándose leves reorientaciones de énfasis vinculadas a los cambios de contexto.

En sintonía con lo que la institución venía articulando desde los años noventa sobre resultados y políticas macroeconómicas en circunstancias de volatilidad de los capitales financieros (CEPAL, 1995; Ffrench Davis, 2005), en el primer quinquenio se profundizó el análisis anterior para evaluar los efectos de las corrientes internacionales de capital en las economías de la región en los períodos de bonanza y caída cíclica. Se hizo hincapié en la importancia de crear una arquitectura financiera mundial y regional y de adoptar políticas nacionales autónomas de fuertes componentes anticíclicos, orientadas a mitigar o compensar los efectos de dichos flujos (Ocampo, 1999a y 1999b; CEPAL, 2000a, 2001a y 2002). Al mismo tiempo, y de diferentes maneras, se fueron rescatando y actualizando las bases estructuralistas del pensamiento de la CEPAL. Desde el punto de vista analítico, si Fajnzylber fue el protagonista de la inauguración del neoestructuralismo, Ocampo fue quien inició su consolidación y perfeccionamiento. ${ }^{13}$

Durante el segundo quinquenio se continuó el trabajo anterior, agregando algunos aspectos que venían al caso dado el contexto expansivo que se estaba viviendo en la región ${ }^{14}$. Por ejemplo, con Machinea se insistió en la necesidad de elaborar mecanismos macroeconómicos anticíclicos como medida preparatoria ante la posible inversión de las coyunturas favorables y de visualizar los desafíos de la región desde una perspectiva que iba mucho más allá del ámbito coyuntural (CEPAL, 2007a). También se siguió avanzando en el análisis de los temas de desarrollo productivo y comercio internacional (CEPAL, 2004a y 2008b), así como de la temática social. Al respecto,

\footnotetext{
${ }^{13}$ Por ejemplo, rescató la idea prebischiana de asimetrías en el orden mundial (Ocampo, 2001; CEPAL, 2002), profundizó el análisis de las condiciones socioeconómicas y de inserción internacional de la región en la era de la globalización (CEPAL, 2002), coordinó un detallado análisis crítico del desempeño de los países en el marco de las reformas (CEPAL, 2001b) e insistió en la importancia de establecer un vínculo entre los estudios macroeconómicos y los análisis microeconómicos del proceso de producción de bienes y servicios, en línea con lo que venía escribiendo Jorge Katz (CEPAL, 1996; Katz, 2000a). Durante este período se fortaleció también el análisis de los aspectos sociales de la realidad regional y se hizo hincapié en la cuestión de la ciudadanía, rescatando la vieja tradición sociológica iniciada 40 años antes por Medina Echavarría (CEPAL, 2002). Asimismo, se amplió el espacio para seguir avanzando en el conocimiento de la problemática relacionada con la conservación del medio ambiente, para lo cual se contó con la contribución de Alicia Bárcena, entre otros.

14 Véase Machinea (2007).
} 
cabe citar el estudio sobre las redes de protección social en América Latina y el Caribe (CEPAL, 2006a), ${ }^{15}$ quizás el de mayor amplitud y alcance que se haya realizado sobre el tema en la región. ${ }^{16}$

\section{La sexta década y las nuevas formulaciones}

Cinco fueron las principales novedades analíticas introducidas en el quehacer de la institución durante el último decenio: un amplio balance del desempeño de los países en el ámbito económico y social tras las reformas liberalizadoras, la perspectiva de agenda para la era global, los conceptos sociopolíticos de ciudadanía y cohesión social, la fusión de los enfoques estructuralista y schumpeteriano y el acento en las políticas macroeconómicas anticíclicas frente a la volatilidad financiera.

Cabe destacar que no se trata de innovaciones teóricas o conceptuales a escala global, sino simplemente de incorporar conceptos y esquemas analíticos novedosos en el pensamiento de la institución o, al menos, de utilizarlos con nuevos énfasis. Pero el hecho de haberlos incorporado revela que, sin perder la referencia analítica tradicional (es decir, la orientación histórico-estructural), el pensamiento de la CEPAL siguió avanzando en su sexta década de existencia con inquietud intelectual y una actitud permanentemente renovadora.

\section{a) Evaluación de los efectos de las reformas sobre la base de los resultados de los años noventa}

El primer aporte de la CEPAL en la última década, a partir del enfoque neoestructuralista, fue el seguimiento y evaluación crítica de los resultados de las reformas. Se analizó el desempeño escasamente favorable de los países de la región en los años noventa, en un esfuerzo de investigación y reflexión realizado entre mediados de 1990 y comienzos de 2000 que se concretó en numerosas publicaciones.

Uno de los documentos que sintetizan este trabajo es Una década de luces y sombras: América Latina y el Caribe en los años noventa (CEPAL, 2001b). ${ }^{17}$ Así,

\footnotetext{
${ }^{15}$ Los colaboradores más importantes de este trabajo fueron Andras Uthoff y Daniel Titelman.

${ }^{16}$ Durante este período se subrayó también la necesidad de crear una institucionalidad regional y de coordinación entre las naciones para afrontar los problemas macroeconómicos (véanse, por ejemplo, Machinea y Rosenwurzel (2005) y Machinea y Titelman (2007), continuando con una reflexión impulsada en el ámbito de un proyecto regional sobre el tema.

${ }^{17}$ El libro fue coordinado por Ocampo, Bajraj y Martín. Véanse también los demás "balances", tales como los de Stallings y Peres (2000); Núñez del Prado (CEPAL/ILPES, 1998) y Ocampo, Franco y Sainz (CEPAL, 2004b).
}

por el lado de las "luces", la obra destaca el control de la inflación y la reducción de los déficits fiscales, el dinamismo exportador, la mayor atracción de inversión extranjera directa, el aumento de productividad de las empresas y sectores líderes, el incremento del gasto social, el mayor énfasis en la problemática del desarrollo ambientalmente sostenible y los avances en materia de democracia y respeto de los derechos humanos. En cuanto a las "sombras", señala el crecimiento económico decepcionante e inestable; la diversificación insuficiente de las exportaciones; el predominio de estrategias defensivas en las empresas nacionales; la reestructuración de los sectores industriales, con resultados muy deficientes en materia de capacidad productiva e innovadora; los grandes déficits externos y la persistencia de la vulnerabilidad externa, exacerbada por la gran inestabilidad de las corrientes de capital. Las sombras incluyen también los mediocres esfuerzos en materia de ahorro e inversión, el aumento del desempleo, la informalidad y la heterogeneidad estructural y la persistente inequidad en la distribución del ingreso.

\section{b) La agenda para la era global}

La segunda novedad se relaciona con la ampliación del paradigma de la transformación productiva con equidad a fin de absorber el concepto de agenda para la era de globalización, que incluyó un conjunto de propuestas sobre las relaciones entre países y pueblos a escala global, el papel crítico del espacio regional y las estrategias nacionales. Fue una idea creada por Ocampo para organizar las recomendaciones en materia de estrategias, instituciones y otros instrumentos de política en estos tres ámbitos (CEPAL, 2002).

El concepto reafirma los principios que se encuentran en los debates de las organizaciones internacionales, a saber: i) suministrar bienes públicos de carácter global tales como democracia, paz, seguridad, estabilidad macroeconómica y financiera o sostenibilidad ambiental; ii) la corrección, empleando mecanismos heterodoxos, de las asimetrías mundiales en tres áreas básicas (productivacomercial, macroeconómica-financiera y movilidad del capital y de la mano de obra), y iii) la incorporación de una agenda social internacional basada en los derechos. En el plano de las estrategias nacionales, abre espacios de reflexión en torno a los desafíos de la globalización en los cuatro campos a que se dedica la CEPAL: macroeconomía y finanzas, transformación productiva, desarrollo social y sostenibilidad ambiental. Además, introduce entre las esferas global y nacional una faceta intermedia relacionada con las recomendaciones en materia de institucionalidad y de política que pueden 
promoverse en el ámbito regional, a fin de respaldar la estabilidad macroeconómica y la integración financiera, productiva y comercial.

\section{c) El enfoque en materia de derechos, ciudadanía y} cohesión social

La tercera innovación corresponde al enfoque relacionado con los derechos, la ciudadanía y la cohesión social. El aspecto sociológico del desarrollo no es un tema nuevo en la producción de la CEPAL, ya que en el pasado estuvo representado por grandes intelectuales del área como Medina Echavarría, Cardoso, Faletto, Graciarena, Woolfe y Gurrieri. En el último tiempo esta perspectiva ha recuperado su importancia en el pensamiento de la institución.

En los estudios anteriores, la cuestión de los conflictos entre las clases sociales ocupaba, inevitablemente, un lugar destacado. Los nuevos análisis, en cambio, centran la atención en las dificultades para ejercer plenamente los derechos de la ciudadanía. Se trata del encuentro con la tradición de defensa de los derechos humanos de las Naciones Unidas que, como se sabe, se inició por la vía de las garantías al ejercicio de los derechos civiles y políticos e incorporó gradualmente el concepto de derechos económicos, sociales y culturales.

El tema se abordó en varios textos, ${ }^{18}$ pero adquirió relevancia en dos de ellos: el documento del período de sesiones de 2000, titulado Equidad, desarrollo y ciudadanía: una visión global (CEPAL, 2000a), y el libro Cohesión social: inclusión y sentido de pertenencia en América Latina y el Caribe (CEPAL, 2007b). ${ }^{19}$

La arquitectura conceptual del mensaje de derechos, ciudadanía y cohesión social se sostiene en torno a cuatro pilares complementarios. El primero consiste en examinar los problemas sociales de la región - pobreza, exclusión, desigualdad de ingresos y riqueza, protección social insuficiente e inadecuada, acceso desigual a los mecanismos de protección existentes, discriminación racial, étnica y cultural— bajo el prisma de un marco ético de derechos humanos, entendidos como universales, indivisibles e interdependientes. El segundo fundamento es que las políticas sociales y la

\footnotetext{
${ }^{18}$ Por ejemplo, en Educación y conocimiento: eje de la transformación productiva con equidad (CEPAL/UNESCO, 1992), ya se destacaba la importancia de la educación para avanzar en el plano de la ciudadanía. En cuanto al uso del concepto de derechos por la CEPAL, véase la reseña de Artigas (2003).

${ }^{19}$ Ernesto Ottone y Martín Hopenhayn participaron en la conceptualización de la cohesión social en ambos documentos. Entre otros textos de la CEPAL sobre el tema, véase, por ejemplo, el libro organizado por Sojo y Uthoff (2007).
}

lucha contra la pobreza deben regirse según los principios de universalidad, solidaridad y eficiencia. El tercero indica que ellas deben tratarse en su totalidad, tanto en lo que se refiere a la necesaria integración con las políticas económicas - ya que ambas son centrales para el desarrollo social - como en cuanto al reconocimiento de la relación virtuosa entre los diferentes beneficios sociales (educación, salud y vivienda, entre otros). El cuarto fundamento consiste en desarrollar una institucionalidad y una práctica democrática que, en esencia, conduzcan a los ciudadanos a integrarse a la vida política y a organizarse para participar en los procesos de toma de decisiones y de implementación de políticas sociales que les permitan satisfacer sus derechos y fortalecer su sentido de pertenencia.

\section{d) La fusión de los enfoques estructuralista y schumpeteriano \\ El balance de los años noventa señala un cuarto} avance, que corresponde a un interesante refinamiento analítico del neoestructuralismo de la CEPAL en el ámbito del desarrollo productivo y la inserción internacional: la fusión de la visión estructuralista y la interpretación schumpeteriana. Esta se originó en los escritos de Fajnzylber de los años ochenta y en el último tiempo ha sido perfeccionada analíticamente por varios autores como Katz, Ocampo y Cimoli.

En esta fusión es posible destacar tres formulaciones complementarias. En primer lugar, de acuerdo con la orientación de Katz, la que se ha expresado en un conjunto de trabajos de evaluación crítica de los efectos de las reformas en el comportamiento productivo de los países de la región y en el ritmo de crecimiento de sus economías, así como en una reflexión sobre las estrategias de transformación y las políticas de desarrollo pertinentes (Katz, 2000a y 2000b).

La segunda es una contribución al análisis de la relación entre la dinámica de la estructura productiva y el crecimiento económico de los países en desarrollo (Ocampo, 2002 y 2005). Dicho estudio comparte el criterio de quienes, como en la CEPAL desde sus orígenes, han considerado que el aumento del PIB per cápita se relaciona con las modificaciones de la composición del producto y de las modalidades de especialización para el comercio internacional. La revisión de los procesos de innovación se integra con la idea de formación de cadenas productivas a partir de los impulsos que promueven potencialmente las innovaciones en función de "aspectos complementarios, vínculos y redes", capaces de generar un "tejido productivo integrado". O sea, aborda el tema de la innovación en el sentido amplio de Schumpeter, 
como la capacidad de crear nuevas actividades y nuevas formas de realizar las existentes.

El tercer planteamiento subraya la importancia del comercio exterior como factor determinante del potencial de crecimiento sostenible a mediano y largo plazos. Este fue perfeccionándose gradualmente y encontró en el documento Progreso técnico y cambio estructural en América Latina (CEPAL, 2007c) su versión hasta ahora más acabada. ${ }^{20}$

Así, la principal restricción de la convergencia es el comportamiento del comercio internacional, medido en función de la elasticidad de las exportaciones y de las importaciones, que es un reflejo de la competitividad de los países. ${ }^{21}$ Por su parte, esta depende del aumento de la productividad de los países en desarrollo respecto de los desarrollados, medida según la brecha tecnológica de la estructura productiva — que, entre otras cosas, refleja el grado de diversificación y la complejidad de las cadenas productivas - y las características no tecnológicas que inciden en la competitividad, tales como financiamiento, institucionalidad y sistemas arancelarios.

El estudio concluye que en América Latina y el Caribe es preciso reorientar la modalidad productiva y exportadora hacia los bienes de mayor contenido tecnológico y, al mismo tiempo, agregar valor mediante cadenas sectoriales de mayor envergadura. Ello permitiría fortalecer el crecimiento, superando el hecho de que el progreso técnico de la región se ha limitado a los enclaves de escasos efectos en la economía en su conjunto, lo que ha fomentado la heterogeneidad estructural, la informalidad laboral, los magros salarios, la pobreza y la concentración del ingreso y la riqueza.

La fusión de los enfoques schumpeteriano y estructuralista no sorprende, dada la prioridad que ambos atribuyen al análisis de las tendencias históricas en el terreno productivo. El acento neoschumpeteriano en la formación y acumulación de conocimiento mediante el proceso de aprendizaje de las empresas, en el efecto de las decisiones del pasado sobre las del presente (pathdependency) y en la modificación de los paradigmas tecnoeconómicos son elementos enriquecedores del enfoque histórico-estructural aplicado por la CEPAL, en su intento por comprender las transformaciones de las

\footnotetext{
${ }^{20}$ Véanse también Cimoli y Correa (2005); Cimoli y otros (2005); Cimoli, Primi y Pugno (2006).

${ }^{21}$ El principal antecedente de este modelo es el multiplicador del comercio exterior de Harrod (1933), reformulado por Kaldor (1966, 1975) y Thirwall (1979) y modificado para la inclusión del concepto de brecha tecnológica por Cimoli, Dosi y Soete (1993). La versión más reciente es de Cimoli y Correa (2005).
}

estructuras productivas en condiciones de subdesarrollo $\mathrm{y}$ heterogeneidad estructural.

En el documento del período de sesiones de 2008, la interpretación se abre a otra novedad analítica en la CEPAL, es decir, la idea de que las nuevas tecnologías permiten que las oportunidades ya no se concentren tan marcadamente en la industria y que se incorporen con intensidad en otros sectores de la economía (CEPAL, 2008). ${ }^{22}$

\section{e) Las políticas macroeconómicas anticíclicas frente a la volatilidad financiera}

En los años noventa, la cuestión de la inestabilidad del crecimiento y su evidente vinculación con la volatilidad de los capitales financieros se convirtió en un tema importante en el programa de la CEPAL. Las primeras manifestaciones de preocupación por este problema ya habían aparecido en algunos documentos de la primera mitad de ese decenio (CEPAL, 1995). A la sazón, se insistía en la necesidad de crear mecanismos capaces de atenuar la entrada de capitales especulativos y sus efectos no deseados. A partir de las crisis de la segunda mitad de la década, el énfasis se trasladó a la construcción de una institucionalidad financiera internacional y regional (CEPAL, 1999 y 2002) y a la elaboración de políticas anticíclicas adecuadas para la conducción de una macroeconomía estable en América Latina y el Caribe (véase CEPAL, 2000a, 2001a, 2002). ${ }^{23}$

En lo que respecta a este último tópico, se pone de relieve que, sin abandonar las conquistas en materia monetaria y fiscal y la estabilidad de precios, la política macroeconómica debe apuntar a sus objetivos reales, es decir, al ritmo y estabilidad del crecimiento económico y al pleno empleo. Al mismo tiempo, se critica agudamente el manejo procíclico de la actividad económica, argumentando que en el ámbito fiscal la política macroeconómica tiende a sobrecalentar la economía y a impedir la formación de reservas para enfrentar las caídas cíclicas y, en los ámbitos monetario y crediticio, a confirmar el efecto extremadamente expansivo de la entrada de capitales mediante el fenómeno de contagio del optimismo entre los agentes económicos y el exceso de endeudamiento y de exposición al riesgo. Se afirma que la inversión del flujo de corrientes externas se traduce en contracción del crédito, pérdida de liquidez de los activos, un efecto riqueza negativo, contracción

\footnotetext{
$22 \mathrm{El}$ énfasis en este punto se debe a Machinea, coordinador del documento.

${ }^{23}$ El tema fue impulsado en los años noventa, principalmente por Ricardo Ffrench-Davis, Gunther Held, Andras Uthoff y Daniel Titelman, y a partir de 1998 obtuvo la colaboración decisiva de Ocampo.
} 
de la economía y restricciones fiscales que impiden contrarrestar los ciclos.

También se sostiene que los problemas se magnifican a causa de sus efectos en el tipo de cambio, cuya valorización con frecuencia excesiva perjudica la inversión en bienes transables y la competitividad durante los períodos de bonanza cíclica, a la vez que genera desequilibrios en la balanza de pagos. Por otra parte, su desvalorización a menudo violenta en las caídas cíclicas tiende a influir negativamente en los precios internos y el patrimonio de los agentes privados y públicos endeudados en moneda extranjera, lo que contribuye a que se produzcan perturbaciones financieras nacionales y a profundizar la recesión, con efectos especialmente perversos para el empleo, los salarios, el gasto público social, la pobreza y la distribución del ingreso. Se señala que la recurrencia de conmociones cíclicas pone de relieve la importancia de contar con redes de protección social eficaces que puedan atender a los sectores sociales más vulnerables durante este tipo de coyunturas. ${ }^{24}$

Asimismo, se ofrece un programa de políticas para enfrentar la volatilidad de los capitales financieros, compuesto de tres elementos: gestión coherente y flexible de las políticas anticíclicas en los ámbitos fiscal, monetario y crediticio; regulación y supervisión prudencial activa del sistema financiero, con un contenido anticíclico, y aplicación de una política de pasivos que dé lugar a que las características de la deuda externa e interna sean adecuadas. Se subraya también el papel que le corresponde a los regímenes cambiarios compatibles con el fortalecimiento de la competitividad.

\section{IV}

\section{La proximidad de los análisis estructuralista y neoestructuralista}

Como ya se ha mencionado, pese a los importantes cambios introducidos a partir de 1990 para adecuarse a las nuevas condiciones históricas, el pensamiento neoestructuralista es muy similar al estructuralista. El prefijo neo viene al caso para indicar la adaptación a los tiempos de apertura y desregulación, pero la base analítica de la nueva etapa sigue siendo estructuralista. El punto es examinado en dos secciones, dedicadas respectivamente a los elementos analíticos clave de ambos períodos y a los análisis en los cuatro grandes campos de reflexión a que se dedica la institución.

Cabe señalar que esa similitud obedeció a tendencias históricas nada favorables. Pese a los importantes avances ocurridos en América Latina en materia de desarrollo productivo, social e institucional, se observa la persistencia de muchos de los factores estructurales del subdesarrollo que angustiaban a Prebisch y a los demás pioneros del estructuralismo latinoamericano. En forma análoga, se conservan hasta hoy muchas de las conclusiones iniciales sobre las tendencias perversas a que daban lugar los fenómenos del subdesarrollo, tales como la inestabilidad macroeconómica; la falta de inversión, progreso técnico y crecimiento; el subempleo o "informalidad"; la mala distribución del ingreso y la pobreza.

\section{Los elementos analíticos clave de ambos períodos}

Son numerosos los ejes que vinculan las formulaciones clásicas del estructuralismo y el neoestructuralismo. Ante todo, el contraste entre la estructura productiva y social de los países latinoamericanos y caribeños y aquella de las naciones desarrolladas ha nutrido en ambas etapas las tesis fundamentales del cuerpo analítico cepalino. En el período estructuralista, se señalaban entre otros aspectos las desfavorables relaciones "centro-periferia", el deterioro de los términos de intercambio, el desequilibrio externo y la inflación estructural, la dinámica de sustitución de importaciones, la integración regional y la dependencia. Por su parte, en la etapa neoestructuralista destacan las ideas relativas a la inserción internacional desfavorable y las asimetrías en la era de la globalización, la vulnerabilidad externa y a los ciclos económicos, el regionalismo abierto y las agendas global, regional y nacional.

\footnotetext{
${ }^{24}$ La temática se abordó, por ejemplo, mediante el análisis del comportamiento procíclico del gasto público social. Al respecto, véanse el Panorama social de América Latina 2000-2001, capítulo IV (CEPAL, 2001c) y el Panorama social de América Latina 2005, capítulo II (CEPAL, 2006b).
} 
En segundo lugar, el mensaje central de ambos períodos contiene la idea de que la contribución del Estado y la movilización social son necesarias para afrontar esos problemas y promover el desarrollo. En la etapa estructuralista se entendía que la industrialización era indispensable para lograr la "convergencia", aunque se consideraba difícil de lograr; en la neoestructuralista se plantea que el desarrollo por la vía de la "transformación productiva con equidad" es fundamental para lograr esa aproximación, pero se lo ve igualmente problemático de alcanzar.

Por último, en ambas etapas las dificultades para alcanzar el desarrollo radican en las características del subdesarrollo latinoamericano y caribeño, definidas esencialmente por medio de tres elementos clave que no se diferencian mayormente entre una y otra. Estos se especificaron en páginas anteriores a los efectos del estructuralismo y en lo que sigue se regresa a ellos para mostrar la proximidad con la fase neoestructuralista.

i) El primer elemento con que se caracteriza el subdesarrollo regional en la fase estructuralista es la escasa diversidad productiva y la especialización en bienes primarios. Ello exige mayores esfuerzos en materia de ahorro y divisas (las dos "brechas") e impone restricciones al crecimiento debido, entre otras cosas, a la vulnerabilidad externa y a la inflación. Similarmente, la visión neoestructuralista argumenta que la falta de diversidad productiva y exportadora se traduce en una baja densidad tecnológica y un reducido encadenamiento entre los sectores, lo que limita el crecimiento a causa de los escasos efectos multiplicadores, la vulnerabilidad externa, la inestabilidad macroeconómica y otros.

ii) El segundo elemento clave del estructuralismo es la heterogeneidad productiva con oferta ilimitada de mano de obra, combinada con baja productividad media, ingresos medios cercanos a los de subsistencia, concentración de la propiedad y distribución desigual del ingreso vinculados al consumo superfluo y pobreza, todo lo cual restringe la inversión y limita el crecimiento. En la etapa neoestructuralista el análisis es muy semejante, es decir, hay heterogeneidad productiva con oferta abundante de mano de obra, informalidad, baja productividad media y pobreza, concentración de la propiedad y del ingreso, asignación insuficiente del ingreso a la acumulación de capital y, por ende, restricciones a la inversión y al crecimiento.

iii) El tercer factor clave de la etapa estructuralista consiste en que el tejido institucional es poco propenso a la acumulación de capital y al progreso técnico, lo que reforzaría la tendencia a la falta de inversión.
En forma análoga, para el neoestructuralismo la lentitud del crecimiento se explica por el hecho de que la institucionalidad existente - definida entre otras cosas por sistemas nacionales de innovación incipientes, Estados no concordantes con las tareas del desarrollo y ausencia de empresas tipo corporaciones globales (global players) — se traduce en una baja inversión en capital físico y en conocimiento. Hay otras dos semejanzas que también son relevantes. En primer lugar, en ambas etapas las interpretaciones sobre la macroeconomía han sido heterodoxas y los análisis sobre la inestabilidad de precios y los niveles de actividad se han centrado en el desequilibrio externo generado por la especialización productiva y, a partir de los años ochenta, también por la nueva configuración del sistema financiero internacional. Segundo, desde fines del decenio de 1970 se ha puesto de relieve la tensión existente entre las condiciones necesarias para el desarrollo sostenible y los patrones universales de consumo y producción que afectan negativamente a la naturaleza.

\section{Continuidad y cambio en las cuatro grandes áreas temáticas de análisis}

El estudio de la evolución de las ideas respecto de los cuatro temas fundamentales a que se ha dedicado la CEPAL permite poner de relieve la continuidad y los cambios de enfoque a lo largo del tiempo. A continuación se hace una breve reseña de ellas.

\section{a) Macroeconomía y finanzas}

La crisis de la deuda de los años ochenta obligó a la CEPAL a centrarse más en la reflexión sobre las cuestiones macroeconómicas y financieras. Sin embargo, ello no significa que antes no se hubiese prestado atención a estos temas. Prueba de ello es el seguimiento sistemático de la coyuntura económica de los países de la región que realiza anualmente en el Estudio económico de América Latina y el Caribe, que en 2008 completó su sexagésima edición. ${ }^{25}$

Podría decirse que hasta 1980 la producción de la CEPAL abarcó tres planteamientos analíticos en el campo de la macroeconomía. En los primeros textos, Prebisch argumentó que la vulnerabilidad externa, que atribuía sobre todo a cuestiones productivas y comerciales, debía enfrentarse con políticas macroeconómicas anticíclicas

\footnotetext{
${ }^{25}$ En relación con los 50 primeros años de esta publicación, véase el artículo de la edición correspondiente a 1997-1998 (CEPAL, 1998c), cuya elaboración estuvo a cargo de José Miguel Benavente.
} 
basadas en el manejo de las divisas y no en la gestión de las políticas fiscales y monetarias, como posteriormente subrayaría la institución. En segundo lugar, en los años cincuenta se sostuvo que en América Latina la inflación no se debía necesariamente a la expansión monetaria, sino a los desajustes en que los estrangulamientos externos cumplían un papel esencial. Este análisis fue conceptuado como "inflación estructural". Por último, como ya se señaló, a lo largo de la década de 1970 la CEPAL advirtió sobre los peligros del excesivo endeudamiento externo. Dichas advertencias fueron premonitorias de la crisis de la deuda y se anticiparon a la posterior preocupación por los efectos de la falta de continuidad de las corrientes internacionales de capital en la estabilidad macroeconómica, tema que adquiriría preponderancia en la institución en las décadas de 1990 y 2000. Tras la crisis de la deuda se inicia una fase de análisis más sostenido y detallado de los desequilibrios macroeconómicos y fiscales y de atención prioritaria a la deuda externa y a los movimientos financieros internacionales, así como a sus repercusiones en materia de solvencia financiera y estabilidad macroeconómica internas. ${ }^{26}$

A partir de los años ochenta, la CEPAL se referiría reiteradamente a su convicción de que era fundamental luchar contra la inflación y buscar el equilibrio fiscal. Como ya se mencionó, al comienzo hubo posiciones distintas sobre la forma de tratar el tema. Sin embargo, en los años noventa se optó por una interpretación heterodoxa respecto de una serie de elementos centrales de la gestión macroeconómica y financiera. Ello se manifiesta al menos en tres aspectos del debate sobre la materia.

El primero es la importancia asignada a la combinación de estabilidad de los precios y del ritmo de crecimiento, esto es, al principio keynesiano de que las políticas monetarias, cambiarias y fiscales deben orientarse simultáneamente a la estabilidad de precios y a la expansión sostenida del nivel de actividad. ${ }^{27}$

En segundo lugar, y en forma complementaria, la heterodoxia se manifiesta en el análisis de los efectos potencialmente perversos de la libre circulación de capitales especulativos en la salud macroeconómica de los países de la región y de los incentivos a la inversión y la competitividad, así como en las recomendaciones

\footnotetext{
${ }^{26}$ En este período se discutió ampliamente el tema de la renegociación de la deuda externa a fin de reabrir espacio al crecimiento económico y al desarrollo. Véase, por ejemplo, Devlin (1984 y 1985).

${ }^{27}$ Este aspecto ha sido reiteradamente destacado por Ricardo FfrenchDavis (2005), por ejemplo, en sus escritos dedicados a "reformar las reformas".
}

de flexibilizar las políticas monetaria y cambiaria para manejar esas corrientes de capital. De acuerdo con este concepto, se ha hecho por lo tanto hincapié en que el control de estas debe hacerse a la vez mediante mecanismos internos y articulando una nueva arquitectura financiera mundial y regional, idea-fuerza emblemática de los años 2000. Subyace toda esta posición la propuesta de que el conjunto de políticas tenga carácter anticíclico, es decir, que ellas den mayor estabilidad al crecimiento de la economía a largo plazo y que eviten sobre todo la apreciación cambiaria debido a sus efectos negativos en la competitividad y la balanza de pagos, que aumentan la vulnerabilidad externa.

Por último, la heterodoxia se manifestó en el énfasis en la regulación y fiscalización rigurosas de las instituciones financieras y del mercado de capitales, así como en la importancia de su estabilidad. Teóricamente, los economistas ortodoxos no discrepaban de la regulación —no podían discrepar del Acuerdo de Basilea I-, pero la reflexión no siempre fue seguida con entusiasmo por ellos, tal vez por las controversias a que da lugar el tema en la comunidad financiera, a menudo renuente a todo tipo de intervención.

b) Transformación productiva y comercio internacional A partir de los textos fundacionales de Prebisch, la CEPAL se ha guiado por la posibilidad teórica de convergencia entre el ingreso por habitante de la región y el de los países desarrollados, en una interpretación de la forma de superar el subdesarrollo que incluye la idea de rendimientos crecientes de escala. Ya en los primeros estudios, y tal como en la versión dada a conocer pocos años después por Lewis (1954), la idea se vinculaba al hecho de que el proceso de industrialización promovía el aumento de capital por trabajador mediante la absorción de trabajadores de los sectores atrasados, en condiciones de oferta abundante de mano de obra a niveles de productividad próximos a los de subsistencia. En estas circunstancias, las economías de la región tendrían un amplio horizonte temporal en que se registrarían marcados aumentos de la productividad media. Se partió de la base de que, en caso de éxito y según el ritmo de acumulación de capital, la industrialización podría permitir que convergieran los niveles de ingreso de la periferia y del centro.

En las formulaciones recientes, la CEPAL ha pasado a ocuparse de la posible convergencia de los países de la región con las naciones desarrolladas, concordando así con las teorías modernas sobre el crecimiento - tanto desde el campo schumpeteriano como de los nuevos planteamientos neoclásicos- como resultado de la rentabilidad no decreciente del capital y del conocimiento 
por trabajador. La visión actual de la institución es que la convergencia depende de la rapidez relativa con que se introduce y difunde el progreso técnico en las estructuras productivas de la región mediante el capital fijo y el conocimiento, en comparación con lo que ocurre en el resto del mundo. Por su parte, se considera que esta rapidez obedece a los cambios en la composición sectorial del producto y a la intensidad del proceso innovador en cada sector de la economía. ${ }^{28}$

Los principales conceptos analíticos utilizados en ambos períodos son, como se dijo, la insuficiente diversidad de la producción y de las exportaciones y la heterogeneidad estructural. En la etapa estructuralista se consideró que existía escasa diversidad de la estructura productiva y especialización en bienes primarios, con bajo crecimiento del comercio internacional, de lo que derivaban una inserción internacional poco favorable al crecimiento y un limitado dinamismo. En la fase neoestructuralista, el diagnóstico consistió en que la competitividad sistémica era reducida, que la especialización productiva y exportadora se centraba en bienes de bajo valor agregado de conocimientos y que había poco dinamismo internacional, escasos encadenamientos productivos internos y una capacidad insuficiente de generación de externalidades. De ello se concluye, igual que en el primer período, que la inserción internacional tiende a ser desfavorable, los problemas de balanza de pagos recurrentes y el crecimiento limitado e inestable.

Del mismo modo, los conceptos de heterogeneidad estructural y subempleo (informalidad, de acuerdo con el lenguaje reciente) son propios de ambas etapas, lo cual tiene dos consecuencias. Por una parte, las dificultades a que dan lugar los efectos potencialmente restrictivos del crecimiento económico. En la primera fase, se sostuvo que había escasez relativa de ahorro e inversión como consecuencia de la reducida productividad media y de la falta de capacidad empresarial. En el período reciente, se afirma que la absorción de mano de obra en los sectores de mayor expansión de la productividad es insuficiente y que en el sector informal ocurre lo contrario, lo cual contribuye a fortalecer la heterogeneidad, a debilitar el aumento de la productividad y, por ende, el crecimiento. Como se verá más adelante, la segunda consecuencia es de índole social, ya que en ambos períodos se considera que la heterogeneidad es un elemento fundamental de la reproducción de la pobreza y la desigualdad.

\footnotetext{
${ }^{28}$ En relación con el tema, véanse, por ejemplo, Hounie y otros (1999) y Cimoli y otros (2005).
}

Por último, en la primera etapa se pusieron de relieve la baja propensión de los agentes productivos a la inversión y al progreso técnico, así como la necesidad de enfrentar esta insuficiencia con una fuerte intervención estatal. En la fase reciente se conserva el concepto de inclinación "rentista" empresarial, pero se combina con las ideas de propensión reducida a la inversión - especialmente en infraestructura-, fragilidad del sistema nacional de innovación y falta de esfuerzo en materia de innovación e investigación y desarrollo. Para afrontar estos problemas, se recomienda fomentar la inversión en bienes públicos en forma selectiva y las asociaciones público-privadas como sustituto del apoyo generalizado del Estado a este proceso.

A su vez, es fácil detectar las analogías entre los mensajes centrales de ambos períodos. En la etapa estructuralista se señalaba que, salvo en caso de éxito total de la industrialización, la inserción internacional continuaría siendo insatisfactoria y que se mantendrían los estrangulamientos externos, un crecimiento escaso e inestable, el desempleo, el subempleo y la pobreza, así como la distancia creciente entre los niveles de riqueza e ingreso del centro y la periferia.

El mensaje actual es parecido, pero en vez de destacar casi en forma exclusiva la industrialización, la nueva estrategia de cambio estructural se articula conceptualmente con la idea de diversificar la producción y las exportaciones, agregando valor por concepto de innovación y ampliando y fortaleciendo el tejido productivo (CEPAL, 2000a, 2002, 2004a, 2008b). En el documento más reciente sobre el tema (CEPAL, 2008b), esta idea se renueva al plantear la posibilidad de abrir oportunidades en numerosos senderos sectoriales y no solo el manufacturero, en que resulta potencialmente factible generar y aprovechar el progreso técnico. El eventual fracaso en la implementación de la estrategia de cambio estructural conduce a que persista una inserción internacional inadecuada, dificultades en la competencia con los países asiáticos, estrangulamientos externos que obstaculizan el crecimiento, creación insuficiente de empleos de calidad, dificultades para superar la pobreza y la desigualdad y una distancia creciente respecto de las naciones desarrolladas.

\section{c) Desarrollo social}

Como ya se señaló, en la década de 1960 la cuestión social pasó a integrar el núcleo central de los estudios de la CEPAL. A la sazón, se diagnosticaba que la pobreza y la mala distribución del ingreso obedecían a la concentración de la propiedad, la heterogeneidad estructural y 
el subempleo, el bajo nivel de remuneraciones resultante del cuadro de baja productividad media y abundancia de mano de obra, así como a la falta de políticas sociales adecuadas. Se sostuvo que la absorción de la oferta de mano de obra se veía limitada por la reducida tasa de inversión y el perfil tecnológico vinculado a la producción de bienes y servicios típicos de los países ricos — destinados a una minoría de la población-, sobre la base de tecnologías importadas desde estos que exigían mucho capital y poco trabajo. Como agravante, se menciona que el excedente de mano de obra no podía emigrar debido a las restricciones internacionales a la libertad de movimiento de los trabajadores. En las diversas interpretaciones de las modalidades o estilos de crecimiento, que constituyen un importante capítulo de la creación analítica de la institución, se relacionaban las estructuras productiva y social.

En la etapa neoestructuralista se concibieron ideas similares a aquellas de la primera época. La interpretación actual es que la pobreza y la distribución del ingreso tienen un carácter estructural, vinculado a la mala distribución de los activos productivos y sociales — crédito, tecnología, información, educación y sistemas de salud, entre otros-y el acceso desigual a ellos, a la heterogeneidad estructural, a la abundancia de mano de obra y a la informalidad laboral, situación agravada por la falta de libertad de movimiento de las corrientes migratorias internacionales ante la oferta excesiva de mano de obra local, en contraposición a la de los bienes y servicios y el capital (CEPAL, 2002). Se hace hincapié en la fragilidad de los mecanismos de acceso a las oportunidades de generación de riqueza tales como educación, tecnología y crédito (CEPAL/UNESCO, 1992 y CEPAL, 2000a) y en la insuficiencia, precariedad e inequidad de las redes de protección social (CEPAL, 2006a). ${ }^{29}$

El pensamiento reciente de la CEPAL se caracteriza por dos conceptos de largo aliento analítico: el de ciudadanía y cohesión social y el de heterogeneidad estructural, que es el elemento más original y permanente de la historia de las ideas cepalinas en materia de pobreza y distribución del ingreso. Prebisch había abordado el fenómeno de la heterogeneidad productiva en los textos fundacionales y, como se dijo, fue considerada como potencialmente permanente por Furtado (1961) y Pinto (1965 y 1970). La idea de estos últimos era que en la

\footnotetext{
${ }^{29}$ En el área social de la CEPAL, el principal mecanismo de difusión es el documento anual titulado Panorama social de América Latina. Sus principales coordinadores a lo largo de las décadas de 1990 y 2000 han sido Rolando Franco, Pedro Sainz, Ernesto Espíndola, Juan Carlos Feres y Arturo León.
}

difusión de la modernidad tienden a conservarse - $-\mathrm{y}$ a veces a ampliarse- el atraso y las profundas diferencias en materia de productividad del trabajo entre sectores y subsectores económicos, regiones y segmentos de la población.

La CEPAL ha defendido, al menos desde el decenio de 1960, la necesidad de una amplia movilización social y política que permita aplicar estrategias de desarrollo que, por una parte, apunten a aumentar y homogeneizar la productividad en la economía y, por otra, a reducir las disparidades sociales en conjunto con una gama de políticas sociales. Son estrategias a las que, desde 1990, se acordó dar a conocer con la feliz expresión de "transformación productiva con equidad".

Ciertamente, sería exagerado afirmar que en el último tiempo la idea de heterogeneidad estructural haya sido el concepto en torno al cual se organizó el programa de reflexión e investigación de la CEPAL. Sin embargo, la lectura sistemática de los textos pertinentes muestra que ella persistió como telón de fondo conceptual en buen número de los estudios sobre la realidad económica y social de la región.

\section{d) Sostenibilidad ambiental}

Los primeros textos sobre desarrollo y medio ambiente elaborados en la CEPAL datan de la primera mitad de la década de 1970 que, como se sabe, fueron años de gran efervescencia en el pensamiento mundial sobre el tema. Es posible que los momentos de mayor impacto y visibilidad internacional hayan coincidido con los documentos difundidos por el Club de Roma respecto de los límites materiales a la expansión mundial de la producción, elaborados a partir de la perspectiva de los países desarrollados, y la respuesta de las Naciones Unidas sustanciada en la Conferencia de las Naciones Unidas sobre el Medio Humano, celebrada en Estocolmo, en 1972, y la creación del Programa de las Naciones Unidas para el Medio Ambiente (PNUMA), en ese mismo año.

El principio ordenador de la segunda iniciativa fue la conciliación de la perspectiva universal de conservación de la naturaleza y la superación de la pobreza en los países en desarrollo. La "tensión" entre desarrollo socioeconómico mundial y conservación del medio ambiente adquiriría en ese momento los contornos básicos con que se manejan hasta la fecha las instituciones y los especialistas que debaten la problemática ambiental en todo el mundo.

Fue en ese contexto, y con el enfoque integrador de sostenibilidad ambiental e inclusión social, que la CEPAL pasó gradualmente a asimilar el tema en su programa de 
investigaciones. La incorporación más definitiva, sobre la base de estudios sistemáticos, tendría lugar algunos años más tarde por medio de un proyecto dirigido por Osvaldo Sunkel entre 1978 y 1980 (Sunkel y Gligo, 1981). No es casual que la orientación adoptada en esa etapa inicial se centrara en los estilos de desarrollo y medio ambiente en América Latina. ${ }^{30}$ Mediante ese enfoque, Sunkel organizaba la reflexión en el formato históricoestructural, de manera coherente con la tradición analítica que había ayudado a crear en la institución.

La novedad respecto de las resoluciones de Estocolmo fue que el enfoque de la CEPAL apuntó a una propuesta más radical, orientada por la idea de modificar el modo de desarrollo de cada país de la región mediante estrategias que permitieran, al mismo tiempo, luchar contra la pobreza y la desigualdad y conservar el medio ambiente. De acuerdo con Sunkel (1971), América Latina estaría sometida a la lógica del estilo que se abría camino a nivel mundial, el capitalismo transnacional. Este tendía a tornarse dominante debido a su rápida penetración en los países en cuanto a amplitud sectorial (widening) y a la profundidad con que se utilizaban sus técnicas productivas en cada sector (deepening) (Sunkel y Fuenzalida, 1979). La adopción de este estilo en América Latina significaría replicar los procesos de producción de uso intensivo de energía, poco adecuados a la dotación de recursos de la región y orientados a una modalidad de consumo que se limita a las elites y se apoya en la absorción cultural del modo de vida de los países ricos.

En los años siguientes, la propuesta de fomentar la sostenibilidad ambiental mediante un cambio radical del estilo de desarrollo fue perdiendo gradualmente su lugar destacado en la producción de la CEPAL. En las décadas de 1990 y 2000, los trabajos avanzaron más bien en estrecha sintonía con los principios de la Declaración de Río sobre el Medio Ambiente y el Desarrollo y de lo que determinaban los distintos acuerdos multilaterales impulsados por las Naciones Unidas desde 1992 y reafirmados en la Cumbre Mundial sobre el Desarrollo Sostenible, realizada en $2002 .{ }^{31}$ La principal referencia

\footnotetext{
${ }^{30}$ Véanse, por ejemplo, Pinto (1970 y 1976), Graciarena (1976), Wolfe (1976), Sunkel (1971) y Sunkel y Fuenzalida (1979). En Villamil (1981) se encuentra una breve reseña de estas publicaciones, preparada en el marco del referido proyecto de 1978-1980.

${ }^{31}$ Es el caso, por ejemplo, de la Convención Marco de las Naciones Unidas sobre el Cambio Climático (CMNUCC), el Convenio sobre la Diversidad Biológica, la Convención de las Naciones Unidas de lucha contra la desertificación en los países afectados por sequía grave o desertificación y el Protocolo de Kyoto de la Convención Marco de las Naciones Unidas sobre el Cambio Climático.
}

analítica pasó a ser el concepto de desarrollo sostenible, entendido como aquel con capacidad de atender las necesidades de la generación actual sin comprometer la satisfacción de las necesidades de las futuras generaciones, organizado en torno a los principios de manejo y protección de los recursos naturales, erradicación de la pobreza y cambio de las modalidades de producción y consumo. 32

Para entender la posición que expresan los textos de la CEPAL en ese contexto, convendría recurrir a tres escenarios hipotéticos diseñados por el PNUMA (2003) para la consecución de los objetivos de desarrollo del Milenio en 2015, especialmente en relación con la sostenibilidad ambiental. El primero resultaría de la subordinación pasiva al crecimiento vinculado con las características mundiales de la producción y el consumo y representaría la continuidad del deterioro ambiental, con graves consecuencias a largo plazo para la humanidad. El segundo marco hipotético también obedecería a la insistencia en el crecimiento económico con las mismas modalidades, pero correspondería a un proceso que implicaría una importante intervención en favor de la conservación ambiental y de la lucha contra la pobreza, con resultados significativos, aunque posiblemente insuficientes en ambos objetivos. El tercero, denominado la "gran transición", se basaría en reformas y políticas radicales, capaces de invertir efectivamente en 2015 el signo de los efectos prevalecientes hasta la fecha en los perfiles globales de consumo y producción, medio ambiente y pobreza.

El último escenario concuerda, aunque con otro nombre, con el cambio de "estilo" en el sentido indicado por Sunkel (1981). Podría sugerirse que, tal como en el trabajo inicial del autor, la CEPAL cobija el sueño del tercer escenario, pero que en la práctica se empeña ante todo por contribuir a la reflexión y análisis sobre el segundo de ellos. De cualquier manera, comprender las dificultades que implica alcanzar este segundo escenario significa participar en una misión que la institución considera ardua y gigantesca, esto es, dotar al estilo ascendente de características básicas de sostenibilidad ambiental y, simultáneamente, otorgarle la capacidad de fomentar una creciente inclusión social.

Para la CEPAL, la agenda ha sido, inevitablemente, luchar contra el temible conjunto de tendencias perversas para la conservación de la naturaleza

\footnotetext{
${ }^{32}$ Gligo (2006) realizó recientemente una interesante interpretación de la reflexión inaugural con motivo de cumplirse los 25 años de la producción intelectual sobre el tema.
} 
provocadas por la actividad humana en todo el mundo, particularmente cambio climático y calentamiento global, desertificación y sequía, disminución de la capa de ozono en la estratosfera, pérdida de diversidad biológica y destrucción de los ecosistemas y movimiento transfronterizo de residuos tóxicos. En cuanto a las cuestiones relacionadas con los temas de pobreza, medio ambiente y modalidades de consumo y producción, el programa lo constituyen los elementos

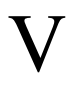

\section{Conclusión}

En este artículo se ha presentado una síntesis de las ideas más relevantes generadas por la CEPAL en sus 60 años de existencia. Asimismo, se han revisado las contribuciones realizadas en su sexto decenio y se ha establecido un paralelo analítico entre las etapas estructuralista, que ocupó las cuatro primeras décadas, y la neoestructuralista, vigente desde 1990.

Una amplia revisión de los estudios realizados por la institución durante estos seis decenios conduce a dos conclusiones importantes. En primer lugar, que el pensamiento generado después de 1990 tiene gran proximidad analítica con el que fue elaborado en las primeras cuatro décadas. Si bien se produjo una adaptación a los tiempos de apertura y globalización, se conservaron los fundamentos del análisis estructuralista del subdesarrollo en América Latina y el Caribe.

La segunda conclusión es que en el último decenio el neoestructuralismo maduró y se enriqueció. La lectura de la extensa producción intelectual del período permite observar que la CEPAL ha absorbido nada menos que cinco nuevos enfoques conceptuales, lo que demuestra la capacidad de renovación de su pensamiento: luces y sombras de los resultados de la región bajo los efectos de las reformas institucionales; agenda para la era global; derechos, ciudadanía y cohesión social; fusión entre los análisis estructuralista y schumpeteriano y perfeccionamiento de los estudios sobre políticas macroeconómicas anticíclicas en épocas de volatilidad de los capitales financieros, vinculadas a la implementación de una nueva arquitectura financiera internacional.

No son pequeños los desafíos analíticos y empíricos que la CEPAL habrá de enfrentar en el futuro. Entre ellos, cabe mencionar el hecho de que los estudios de la institución abarcan un elevado número de países cuyas configuración macroeconómica y características que se han destacado en las diferentes conferencias mundiales como áreas de acción prioritaria, es decir, agua y saneamiento, energía, salud y agricultura, entre otras. Esta orientación general de los trabajos se manifestó especialmente a partir de fines de los años noventa, cuando la institución empezó a buscar una interacción más cercana con las iniciativas sobre desarrollo sostenible promovidas en el ámbito de los demás organismos de las Naciones Unidas. ${ }^{33}$ productivas, sociales y ambientales son muy diferentes entre sí. Al mismo tiempo, deberá considerar la rapidez e intensidad de los cambios en todos los grandes temas a que se dedica y que el hecho de estudiarlos implica afrontar una gran incertidumbre. Es el caso, por ejemplo, de las repercusiones de la actual crisis financiera internacional y de las oscilaciones del comercio mundial en la salud macroeconómica de los países de la región; de los efectos — nada precisos — de la intensa revolución tecnológica mundial en materia de productividad, competitividad y comercio, así como de las consecuencias de la relativa escasez de recursos naturales en varios países. También deben considerarse los numerosos factores de imprevisibilidad de las tendencias sociales y la amenaza que la destrucción del medio ambiente representa para la humanidad, los que se prestan a las más diversas hipótesis.

El trabajo que viene realizando la CEPAL ciertamente admite perfeccionamientos, cuyo análisis escapa el ámbito de esta nota final. Entre ellos, cabe mencionar una mayor interacción entre los diferentes campos de estudio y la profundización del conocimiento sobre la región mediante la sistematización de las diferencias entre los países y sus patrones específicos de desarrollo real y potencial. Esto último sigue siendo una tarea pendiente de la institución, así como una obligación para con la región.

\footnotetext{
${ }^{33}$ Alicia Bárcena, actual Secretaria Ejecutiva de la CEPAL, ha sido la principal responsable de la renovación que tuvo lugar cuando llegó a la institución en calidad de directora de la División de Desarrollo Sostenible y Asentamientos Humanos. Véanse, por ejemplo, Bárcena y otros (2002), Bárcena y de Miguel (2003) y Bárcena y otros (2004).
} 
La capacidad analítica y las bases de datos de que dispone la CEPAL son mecanismos suficientes para enfrentar estos y otros osados emprendimientos. Además, como se argumentó a lo largo del presente trabajo, la institución ha demostrado tener capacidad para adaptarse a las nuevas realidades y salir al encuentro de los nuevos desafíos. Es probable que el historiador al que dentro de 10 años se le pida sistematizar el pensamiento del séptimo decenio de actividades se incline, como ocurrió con quien estudió el sexto, ante un rico acervo de producción intelectual.

\section{Bibliografía}

Amsden, A. (1989), Asia's Next Giant. South Korea and Late Industrialization, Nueva York, Oxford University Press.

Artigas, Carmen (2003), "La incorporación del concepto de derechos económicos, sociales y culturales al trabajo de la CEPAL: reseña de algunas lecturas pertinentes", serie Políticas sociales, $\mathrm{N}^{\mathrm{o}} 72$ (LC/L.1964-P), Santiago de Chile, Comisión Económica para América Latina y el Caribe (CEPAL), septiembre. Publicación de las Naciones Unidas, $\mathrm{N}^{\circ}$ de venta: S.03.II.G.123.

Bárcena, Alicia y Carlos de Miguel (comps.) (2003), Financiamiento para el desarrollo sostenible: visiones y acciones desde la perspectiva de América Latina y el Caribe (LC/L.1875-P), Santiago de Chile, Comisión Económica para América Latina y el Caribe (CEPAL).

Bárcena, Alicia y otros (comps.) (2004), "Los transgénicos en América Latina y el Caribe: un debate abierto", Libros de la CEPAL, $\mathrm{N}^{\circ} 78$ (LC/G.2227-P), Santiago de Chile, Comisión Económica para América Latina y el Caribe (CEPAL). Publicación de las Naciones Unidas, $\mathrm{N}^{\mathrm{o}}$ de venta: S.04.II.G.74.

(2002), "Financiamiento para el desarrollo sostenible en América Latina y el Caribe: de Monterrey a Johannesburgo" (LC/R.2098), Santiago de Chile, Comisión Económica para América Latina y el Caribe (CEPAL).

Bielschowsky, Ricardo (1998), "Cincuenta años del pensamiento de la CEPAL: una reseña", Cincuenta años del pensamiento de la CEPAL: textos seleccionados, Santiago de Chile, Comisión Económica para América Latina y el Caribe (CEPAL)/Fondo Cultura Económica.

Cardoso, Fernando Henrique (1977), "La originalidad de la copia: la CEPAL y la idea del desarrollo", Revista de la CEPAL, $\mathrm{N}^{\circ} 4$, Santiago de Chile, Comisión Económica para América Latina y el Caribe (CEPAL), segundo semestre.

Cardoso, Fernando Henrique y Enzo Faletto (1969), Dependencia y desarrollo en América Latina, México, D.F., Siglo Veintiuno.

CEPAL (Comisión Económica para América Latina y el Caribe) (2008a), La transformación productiva 20 años después. Viejos problemas, nuevas oportunidades (LC/G.2367(SES.32/3)), Santiago de Chile, mayo.

(2008b), La transformación productiva 20 años después: viejos problemas, nuevas oportunidades. Síntesis (LC/G.2368P(SES.32/4)), Santiago de Chile.

(2007a), Panorama social de América Latina 2006 (LC/G.2326-P), Santiago de Chile. Publicación de las Naciones Unidas, $\mathrm{N}^{\circ}$ de venta: S.06.II.G.133.

(2007b), Cohesión social: inclusión y sentido de pertenencia en América Latina y el Caribe (LC/G.2335/Rev.1), Santiago de Chile, Comisión Económica para América Latina y el Caribe (CEPAL)/Secretaría General Iberoamericana.

(2007c), "Progreso técnico y cambio estructural en América Latina", Documentos de proyectos, $\mathrm{N}^{\circ} 136$ (LC/W.136), Santiago de Chile, Comisión Económica para América Latina y el Caribe (CEPAL), octubre.

(2007d), Estudio económico de América Latina y el Caribe 2006-2007 (LC/G.2338-P), Santiago de Chile. Publicación de las Naciones Unidas, $\mathrm{N}^{\mathrm{o}}$ de venta: S.07.II.G.2. (2006a), La protección social de cara al futuro: acceso, financiamiento y solidaridad (LC/G.2294(SES.31/3)), Santiago de Chile.

(2006b), Panorama social de América Latina, 2005

(LC/G.2288-P), Santiago de Chile. Publicación de las Naciones Unidas, $\mathrm{N}^{\mathrm{o}}$ de venta: S.05.II.G.161.

(2004a), Desarrollo productivo en economías abiertas (LC/G.2334(SES.30/3)), Santiago de Chile.

(2004b), "Una década de desarrollo social en América Latina, 1990-1999", Libros de la CEPAL, No 77 (LC/G.2212-P), Santiago de Chile. Publicación de las Naciones Unidas, $\mathrm{N}^{\mathrm{o}}$ de venta: S.03.II.G.143.

(2002), Globalización y desarrollo (LC/G.2157(SES.29/3)),

Santiago de Chile, Comisión Económica para América Latina y el Caribe (CEPAL).

(2001a), Crecer con estabilidad: el financiamiento del desarrollo en el nuevo contexto internacional, Santafé de Bogotá, Alfaomega/Comisión Económica para América Latina y el Caribe (CEPAL).

(2001b), Una década de luces y sombras: América

Latina y el Caribe en los años noventa, Santafé de Bogotá, Alfaomega/Comisión Económica para América Latina y el Caribe (CEPAL).

(2001c), Panorama social de América Latina 2000-2001

(LC/G.2138-P), Santiago de Chile. Publicación de las Naciones Unidas, $\mathrm{N}^{\circ}$ de venta: S.01.II.G.141.

(2000a), Equidad, desarrollo y ciudadanía (LC/G.2071/ Rev.1-P), Santiago de Chile, Comisión Económica para América Latina y el Caribe (CEPAL). Publicación de las Naciones Unidas, $\mathrm{N}^{\mathrm{o}}$ de venta: S.00.II.G.81.

(2000b), La brecha de la equidad: una segunda evaluación (LC/G.2096), Santiago de Chile.

(1999), Hacia una nueva arquitectura financiera internacional: informe del Grupo de Trabajo del Comité Ejecutivo de Asuntos Económicos y Sociales de las Naciones Unidas, 21 de enero de 1999 (LC/G.2054), Santiago de Chile.

(1998a), Cincuenta años del pensamiento de la CEPAL: textos seleccionados, Santiago de Chile, Comisión Económica para América Latina y el Caribe (CEPAL)/Fondo Cultura Económica.

(1998b), "El pacto fiscal: fortalezas, debilidades, desafíos", Libros de la CEPAL, No 47 (LC/G.1997/Rev.1-P), Santiago de Chile. Publicación de las Naciones Unidas, $\mathrm{N}^{\circ}$ de venta: S.98. II.G.5.

(1998c), "Cincuenta años del estudio económico", Estudio económico de América Latina y el Caribe 1997-1998 (LC/ G.2032-P), Santiago de Chile, tercera parte. Publicación de las Naciones Unidas, $\mathrm{N}^{\circ}$ de venta: S.98.II.G.2. Antes 1998d

(1996), "Fortalecer el desarrollo: interacciones entre macro y microeconomía", Libros de la CEPAL, No 42 (LC/G.1898/ Rev.1-P), Santiago de Chile. Publicación de las Naciones Unidas, $\mathrm{N}^{\mathrm{o}}$ de venta: S.96.II.G.2.

(1995), "América Latina y el Caribe: políticas para mejorar la inserción en la economía mundial", Libros de la CEPAL, $\mathrm{N}^{\circ} 40$ 
(LC/G.1800/Rev.1-P), Santiago de Chile. Publicación de las Naciones Unidas, $\mathrm{N}^{\circ}$ de venta: S.95.II.G.6.

(1994), "El regionalismo abierto en América Latina y el Caribe: la integración económica al servicio de la transformación productiva con equidad", Libros de la CEPAL, No 39 (LC/G.1801/ Rev.1-P), Santiago de Chile. Publicación de las Naciones Unidas, $\mathrm{N}^{\circ}$ de venta: S.94.II.G.3.

(1992), "Equidad y transformación productiva: un enfoque integrado", Libros de la CEPAL, No 32 (LC/G.1701/Rev.1-P), Santiago de Chile. Publicación de las Naciones Unidas, $\mathrm{N}^{\circ}$ de venta: S.92.II.G.5.

(1990), "Transformación productiva con equidad: la tarea prioritaria del desarrollo de América Latina y el Caribe en los años noventa", Libros de la CEPAL, No 25 (LC/G.1601-P), Santiago de Chile. Publicación de las Naciones Unidas, $\mathrm{N}^{\circ}$ de venta: S.90.II.G.6.

(1971), Estudio económico de América Latina y el Caribe, 1971 (E/CN.12/935/Rev.1), Santiago de Chile. Publicación de las Naciones Unidas, $\mathrm{N}^{\circ}$ de venta: S.73.II.G.I.

(1969), El pensamiento de la CEPAL, Santiago de Chile, Editorial Universitaria.

(1959), El Mercado Común Latinoamericano (E/CN.12/531), Santiago de Chile. Publicación de las Naciones Unidas, $\mathrm{N}^{\mathrm{o}}$ de venta: 59.II.G.4.

(1955), Introducción a la técnica de programación (E/CN.12/363), Santiago de Chile.

(1951a), Estudio económico de América Latina 1950 (E/CN.12/217), Santiago de Chile.

(1951b), Estudio económico de América Latina 1949 (E/CN.12/164/Rev.1), Santiago de Chile.

CEPAL/ILPES (Comisión Económica para América Latina y el Caribe/ Instituto Latinoamericano y del Caribe de Planificación Económica y Social) (2004), Panorama de la gestión pública (LC/IP/L.243), Santiago de Chile.

(1998), "Reflexiones sobre el desarrollo y la responsabilidad del Estado", Santiago de Chile.

CEPAl/Unesco (Comisión Económica para América Latina y el Caribe/Organización de las Naciones Unidas para la Educación, la Ciencia y la Cultura) (1992b), "Educación y conocimiento: eje de la transformación productiva con equidad", Libros de la CEPAL, No 33 (LC/G.1702/Rev.2-P), Santiago de Chile. Publicación de las Naciones Unidas, $\mathrm{N}^{\mathrm{o}}$ de venta: S.92.II.G.6.

Cimoli, Mario (comp.) (2005), Heterogeneidad estructural, asimetrías tecnológicas y crecimiento en América Latina (LC/W.35), Santiago de Chile, Comisión Económica para América Latina y el Caribe (CEPAL).

Cimoli, Mario y Nelson Correa (2005), "La apertura comercial y la brecha tecnológica en América Latina: una trampa de bajo crecimiento", Más allá de las reformas: dinámica estructural y vulnerabilidad macroeconómica, José Antonio Ocampo (comp.), Bogotá, D.C., Alfaomega/Comisión Económica para América Latina y el Caribe (CEPAL).

Cimoli, Mario y otros (2005), Cambio estructural, heterogeneidad productiva y asimetrías tecnológicas y crecimiento en América Latina, Mario Cimoli (comp.), Santiago de Chile, Comisión Económica para América Latina y el Caribe (CEPAL)/Banco Interamericano de Desarrollo (BID).

Cimoli, Mario, Giovanni Dosi y Luc Soete (1993), "Innovation, diffusion, institutional differences and patterns of trade: a north-south model", Technology Diffusion and Economic Growth. International and National Policy Perspectives, vol. 3, P.A. David y G. Dosi Arcangeli (comps.), Nueva York, Oxford University Press,

Cimoli, Mario, Annalisa Primi y Mauricio Pugno (2006), “Un modelo de bajo crecimiento: la informalidad como restricción estructural", Revista de la CEPAL, No 88 (LC/G.2289-P), Santiago de Chile, Comisión Económica para América Latina y el Caribe (CEPAL), abril.
Devlin, Robert (1985), "Deuda externa y crisis: el ocaso de la gestión ortodoxa", Revista de la CEPAL, N 27 (LC/G.1368), Santiago de Chile, diciembre.

(1984), "La carga de la deuda y la crisis: ¿se deberá llegar a una solución unilateral?", Revista de la CEPAL, No 22 (E/ CEPAL/G.1296), Santiago de Chile, abril.

Fajnzylber, Fernando (1990), "Industrialización en América Latina: de la 'caja negra' al "casillero vacío", Cuadernos de la CEPAL, $\mathrm{N}^{\circ} 60$ (LC/G.1534/Rev.1-P), Santiago de Chile, Comisión Económica para América Latina y el Caribe (CEPAL). Publicación de las Naciones Unidas, $\mathrm{N}^{\mathbf{0}}$ de venta: S.89.II.G.5.

(1983), La industrialización trunca de América Latina, México, D.F., Editorial Nueva Imagen, S.A.

Ffrench-Davis, Ricardo (comp.) (2005), Macroeconomía, comercio y finanzas para reformar las reformas en América Latina, Bogotá, D.C., Mayol Ediciones/Comisión Económica para América Latina y el Caribe (CEPAL).

Fitzgerald, E.V.K (1994), "ECLAC and the formation of Latin American economic doctrine", Latin America in the 1940s: War and Post War Transitions, D. Rock (comp.), Los Angeles, California, California University Press.

Furtado, Celso (1969), "Desarrollo y estancamiento en América latina: un enfoque estructuralista”, Investigación económica, vol. 29, $\mathrm{N}^{\mathrm{o}}$ 113, México, D.F., Universidad Nacional Autónoma de México, febrero-marzo.

(1961), Desenvolvimento e subdesenvolvimento, Río de Janeiro, Fundo de Cultura.

(1959), Formação econômica do Brasil, Río de Janeiro, Fundo de Cultura.

Gligo, Nicolo (2006), "Estilos de desarrollo y medio ambiente en América Latina, un cuarto de siglo después", serie Medio ambiente y desarrollo, № 126 (LC/L.2533-P), Santiago de Chile, Comisión Económica para América Latina y el Caribe (CEPAL), mayo. Publicación de las Naciones Unidas, $\mathrm{N}^{\circ}$ de venta: S.06.II.G.60.

Graciarena, Jorge (1976), "Poder y estilos de desarrollo: una perspectiva heterodoxa", Revista de la CEPAL, № 1, Santiago de Chile, primer semestre.

Gurrieri, Adolfo (ed.) (1982), Obra de Raúl Prebisch en la CEPAL, México, D.F., Fondo de Cultura Económica.

Harrod, R.F. (1933), International Economics, Cambridge, Cambridge University Press.

Hettne, Bjorn (1995), Development Theory and the Three Worlds: Towards an International Political Economy of Development, Londres, Longman.

Hirschman, Albert (1963), "Ideologías de desarrollo económico en América Latina”, Controversia sobre Latinoamérica, A. Hirschman (comp.), Buenos Aires, Instituto Torcuato Di Tella.

(1958), The Strategy of Economic Development, New Haven, Yale University Press.

Hodara, J. (1987), Raúl Prebisch y la CEPAL: sustancia, trayectoria y contexto institucional, México, D.F., El Colegio de México.

Hounie, A. y otros (1999), "La CEPAL y las nuevas teorías del crecimiento", Revista de la CEPAL, No 68 (LC/G.2039-P), Santiago de Chile, agosto.

Kaldor, N. (1975), "What is wrong with economic theory?", Quarterly Journal of Economics, vol. 89, № 3, Cambridge, Massachusetts, The MIT Press, agosto.

(1966), Causes of the Slow Rate of Economic Growth in the United Kingdom, Cambridge, Cambridge University Press.

Katz, Jorge (2000a), Reformas estructurales, productividad y conducta tecnológica en América Latina, Santiago de Chile, Comisión Económica para América Latina y el Caribe (CEPAL)/Fondo de Cultura Económica.

(2000b), "Structural change and labor productivity growth in Latin American manufacturing industries", World Development, vol. 28, $\mathrm{N}^{\circ}$ 9, Amsterdam, Elsevier.

Lerda, Juan Carlos (2008), "Pacto fiscal, diez años después", Santiago de Chile, inédito. 
Lewis, A. (1954), "Economic development with unlimited supplies of labour", Manchester School of Economic and Social Studies, vol. 22, $\mathrm{N}^{\mathrm{o}} 2$, Manchester.

Love, Joseph (2005), "The rise and decline of economic structuralism in Latin America: new dimensions", Latin American Research Review, vol. 40, № 3, Pittsburgh, Latin American Studies Association.

Macario, S. (1964), "Proteccionismo e industrialización en América Latina”, Boletín económico de América Latina, vol. 9, № 1 , Santiago de Chile, marzo.

Machinea, José Luis (2007), "Ideas para una agenda de desarrollo", Pensamiento iberoamericano (segunda época), $\mathrm{N}^{\circ} 0$, Madrid, Fundación Carolina.

Machinea, José Luis y Guillermo Rozenwurcel (2005), "Macroeconomic coordination in Latin America: does it have a future?", serie Informes y estudios especiales, $\mathrm{N}^{\circ} 15$ (LC/L.2431-P), Santiago de Chile, Comisión Económica para América Latina y el Caribe (CEPAL), diciembre. Publicación de las Naciones Unidas, $\mathrm{N}^{\circ}$ de venta: E.05.II.G.177.

Machinea, José Luis y Daniel Titelman (2007), “¿Un crecimiento menos volátil?: el papel de las instituciones financieras regionales", Revista de la CEPAL, $\mathrm{N}^{\circ} 91$ (LC/G.2333-P), Santiago de Chile, Comisión Económica para América Latina y el Caribe (CEPAL), abril.

Marinho, Luiz Claudio (1991), "La CEPAL y las concepciones del desarrollo en América Latina”, La crisis económica en América Latina, Pedro Talavera (coord.), Barcelona, Sendai Ediciones.

Noyola Vázquez, J. (1957), "Inflación y desarrollo económico de Chile y México", Panorama económico, vol. 11, № 170, Santiago de Chile, julio.

Ocampo, José Antonio (comp.) (2005), Más allá de las reformas: dinámica estructural y vulnerabilidad macroeconómica, Bogotá, D.C., Alfaomega/Comisión Económica para América Latina y el Caribe (CEPAL).

(2004), "Lights and shadows in Latin American structural reforms", Economic Reforms Growth and Inequality in Latin America: Essays in Honor of Albert Berry, Gustavo Indart (ed.), Aldershot, Ashgate.

(2002), "Structural dynamics and economic development", Social Institutions and Economic Development. A Tribute to Kurt Martin, Valpy FitzGerald (comp.), Dordrecht, Instituto de Estudios Sociales Dordrecht Kluwer.

(2001), "Raúl Prebisch y la agenda del desarrollo en los albores del siglo XXI", Revista de la CEPAL, No 75 (LC/G.2150-P), Santiago de Chile, Comisión Económica para América Latina y el Caribe (CEPAL), diciembre.

(1999a), La reforma del sistema financiero internacional: un debate en marcha, Santiago de Chile, Comisión Económica para América Latina y el Caribe (CEPAL)/Fondo de Cultura Económica.

(1999b), "La reforma financiera internacional: una agenda ampliada", Revista de la CEPAL, No 69 (LC/G.2067-P/E), Santiago de Chile, Comisión Económica para América Latina y el Caribe (CEPAL), diciembre.

Pazos, F. (1983), "Cincuenta años de pensamiento económico en América Latina”, El trimestre económico, vol. 50(4), № 200, México, D.F., Fondo de Cultura Económica, octubre-diciembre.

Pinto, Aníbal (1976), "Notas sobre los estilos de desarrollo en América Latina", Revista de la CEPAL, $\mathrm{N}^{\circ} 1$, Santiago de Chile, primer semestre.

(1970), "Naturaleza e implicaciones de la "heterogeneidad estructural" de la América Latina", El trimestre económico, vol. 37(1), No 145, México, D.F., Fondo de Cultura Económica, enero-marzo.

(1965), "Concentración del progreso técnico y de sus frutos en el desarrollo de América Latina", El trimestre económico, vol. 32(1), $\mathrm{N}^{\circ} 125$, enero-marzo.
PNUMA (Programa de las Naciones Unidas para el Medio Ambiente) (2003), GEO América Latina y el Caribe: perspectivas del medio ambiente, 2003, México, D.F., Oficina Regional para América Latina y el Caribe/Observatorio del Desarrollo.

Prebisch, Raúl (1973), Problemas teóricos y prácticos del crecimiento económico, Santiago de Chile, Comisión Económica para América Latina y el Caribe (CEPAL).

(1982), "Desarrollo económico, planeación y cooperación internacional", Obra de Raúl Prebisch en la CEPAL, Adolfo Gurrieri (comp.), México, D.F., Fondo de Cultura Económica.

(1961), "El falso dilema entre el desarrollo y la estabilidad monetaria", Boletín económico de América Latina, vol. 6, № 3, Santiago de Chile.

(1949), El desarrollo económico de la América Latina y algunos de sus principales problemas (E/CN.12/89), Santiago de Chile, Comisión Económica para América Latina y el Caribe (CEPAL).

Rodríguez, Octavio (2006), El estructuralismo latinoamericano, México, D.F., Siglo Veintiuno/Comisión Económica para América Latina y el Caribe (CEPAL).

(1981), La teoría del subdesarrollo de la CEPAL, México, D.F., Siglo Veintiuno.

Rosenthal, Gert (2004), "ECLAC: a commitment to a Latin American way", Unit and Diversity in Development Ideas: Perspectives from the UN Regional Commissions, Yves Berthelot (comp.), Bloomington, Indiana University Press.

Sojo, Ana y Andras Uthoff (comps.) (2007), "Cohesión social en América Latina y el Caribe: una revisión perentoria de algunas de sus dimensiones", Documentos de proyectos, № 120 (LC/W.120), Santiago de Chile, Comisión Económica para América Latina y el Caribe (CEPAL).

Stallings, Barbara y Wilson Peres (2000), Crecimiento, empleo y equidad: el impacto de las reformas económicas en América Latina y el Caribe, Santiago de Chile, Fondo de Cultura Económica/Comisión Económica para América Latina y el Caribe (CEPAL).

Sunkel, Osvaldo (1991), El desarrollo desde dentro, un enfoque neoestructuralista para la América Latina, México, D.F., Fondo de Cultura Económica.

(1981), "La interacción entre los estilos de desarrollo y medio ambiente en la América Latina", Estilos de desarrollo y medio ambiente en la América Latina, Osvaldo Sunkel y Nicolo Gligo (comps.), México, D.F., Fondo de Cultura Económica.

(1971), "Capitalismo trasnacional y desintegración nacional en América Latina", El trimestre económico, № 150, México, D.F., Fondo de Cultura Económica, abril-junio.

(1967), "Política nacional de desarrollo y dependencia externa", Estudios internacionales, vol. 1, № 1, Santiago de Chile.

(1958), "La inflación chilena: un enfoque heterodoxo", $E l$ trimestre económico, vol. 25(4), № 100, México, D.F., Fondo de Cultura Económica, octubre-diciembre.

Sunkel, Osvaldo y Nicolo Gligo (comps.) (1981), Estilos de desarrollo y medio ambiente en la América Latina, México, D.F., Fondo de Cultura Económica.

Sunkel, Osvaldo y E. Fuenzalida (1979), “Transnationalization and its national consequences", Transnational Capitalism and National Development, J. Villamil (comp.), Brighton, Reino Unido, Harvester Press.

Sunkel, Osvaldo y Pedro Paz (1970), Subdesarrollo latinoamericano y la teoría del desarrollo, México, D.F., Siglo Veintiuno.

Taylor, Lance y Ellen Shapiro (1990), "The state and industrial strategy”, World Development, vol. 18, № 6, Amsterdam, Elsevier.

Tavares, Maria da Conceição (1964), "Auge y declinación del proceso de sustitución de importaciones en el Brasil", Boletín económico de América Latina, vol. 9, № 1, Santiago de Chile, Comisión Económica para América Latina y el Caribe (CEPAL), marzo.

Tavares, Maria da Conceição y José Serra (1971), "Más allá del estancamiento", El trimestre económico, vol. 38(4), № 152, México, D.F., Fondo de Cultura Económica, noviembre-diciembre. 
Thirwall, Anthony P. (1979), "Balance of payments constraint as an explanation of international growth rate differences", Quarterly Review. Banca Nazionale del Lavoro, № 128, Roma, Banca Nazionale del Lavoro, marzo.

Torres, Miguel (comp.) (2006), "Fernando Fajnzylber. Una visión renovadora del desarrollo en América Latina", Libros de la CEPAL, No 92 (LC/G.2322-P), Santiago de Chile. Publicación de las Naciones Unidas, $\mathrm{N}^{\mathrm{o}}$ de venta: S.06.II.G.124.

Urquidi, V. (1998), "Incidentes de la integración en Centroamércia y Panamá, 1952-1958”, Revista de la CEPAL, número extraordinario, Santiago de Chile, octubre.
Villamil, José J. (1981), “Concepto de estilos de desarrollo: una aproximación", Estilos de desarrollo y medio ambiente en la América Latina, Osvaldo Sunkel y Nicolo Gligo (comps.), México, D.F., Fondo de Cultura Económica.

Wade, R. (1990), Governing the Market Economic Theory and the Role Government in East Asian Industrialization, Princeton, Princeton University Press.

Williamson, John (1990), The Washington Consensus, Washington, D.C. Wolfe, Marshall (1976), "Enfoques del desarrollo: ¿de quién y hacia qué?" Revista de la CEPAL, $\mathrm{N}^{\circ} 1$, Santiago de Chile, primer semestre. 